\title{
Minocycline as a treatment for traumatic brain injury-induced impulsive and attentional deficits
}

\author{
Kristen M. Pechacek \\ kmp0033@mix.wvu.edu
}

Follow this and additional works at: https://researchrepository.wvu.edu/etd

Part of the Biological Psychology Commons, and the Other Psychology Commons

\section{Recommended Citation}

Pechacek, Kristen M., "Minocycline as a treatment for traumatic brain injury-induced impulsive and attentional deficits" (2020). Graduate Theses, Dissertations, and Problem Reports. 7938.

https://researchrepository.wvu.edu/etd/7938

This Thesis is protected by copyright and/or related rights. It has been brought to you by the The Research Repository @ WVU with permission from the rights-holder(s). You are free to use this Thesis in any way that is permitted by the copyright and related rights legislation that applies to your use. For other uses you must obtain permission from the rights-holder(s) directly, unless additional rights are indicated by a Creative Commons license in the record and/ or on the work itself. This Thesis has been accepted for inclusion in WVU Graduate Theses, Dissertations, and Problem Reports collection by an authorized administrator of The Research Repository @ WVU. For more information, please contact researchrepository@mail.wvu.edu. 
Minocycline as a treatment for traumatic brain injury-induced impulsive and attentional deficits

Kristen M. Pechacek

Thesis submitted to the

Eberly College of Arts and Sciences

at West Virginia University

in partial fulfillment of the requirements for the degree of

Master of Science in

Psychology

Cole Vonder Haar, PhD., Chair

Steven Kinsey, Ph.D.

Elizabeth Engler-Chiurazzi, Ph.D.

Department of Psychology

Morgantown, West Virginia

2020

Keywords: traumatic brain injury, impulsivity, attention, minocycline, neuroinflammation Copyright 2020 Kristen Pechacek 


\begin{abstract}
Minocycline as a treatment for traumatic brain injury-induced impulsive and attentional deficits
\end{abstract}

Kristen M. Pechacek

Traumatic brain injury (TBI) impacts millions worldwide and can cause lasting psychiatric symptoms. Chronic neuroinflammation is a characteristic of post-injury pathology and is positively associated with psychiatric conditions such as ADHD and bipolar disorder. Therefore, the current study sought to treat TBI-induced impulsivity and inattention using minocycline, an antibiotic with anti-inflammatory properties. Rats were trained on the five-choice serial reaction time task (5CSRT), a measure of motor impulsivity and attention. After behavior was stable on the 5CSRT, rats received either a bilateral frontal TBI or sham procedure. Minocycline was given at either $1 \mathrm{~h}$ post-injury or beginning at 8 weeks after injury. The minocycline treatment consisted of $45 \mathrm{mg} / \mathrm{kg}$ via intraperitoneal injections given every $12 \mathrm{~h}$ for 5 days. Behavioral testing on the 5CSRT began again after one week of recovery and continued for 12 weeks postinjury, then rats were transcardially perfused. Impulsivity and inattention were both substantially increased following TBI. Minocycline at both the early ( $1 \mathrm{~h}$ post-injury) and late ( 8 weeks postinjury) time points failed to affect TBI-induced impulsivity and inattention. TBI rats had increased lesion volume, but minocycline did not attenuate the lesion size. Additionally, microglia levels measured by IBA- $1^{+}$cells did not differ between TBI and sham rats, and minocycline did not differentially change the number of microglia in TBI rats. Based on the results of this study, minocycline does not appear to be an effective treatment for post-injury psychiatric-like symptoms. 


\section{Table of Contents}

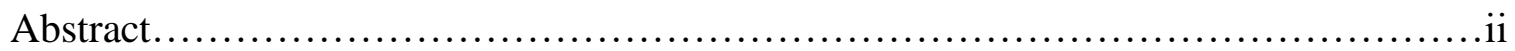

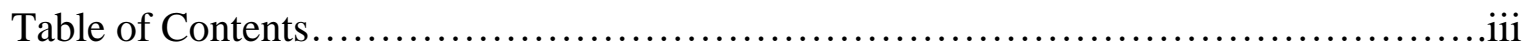

Introduction...............................................................

Methods.......................................................................

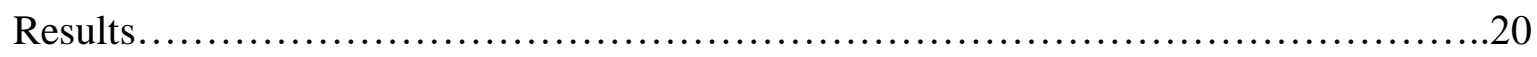

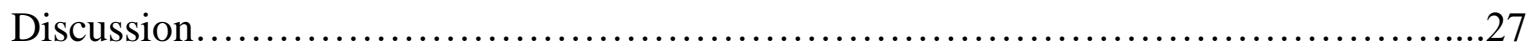

Appendices............................................................ 38

References................................................................ 41 
Minocycline as a treatment for traumatic brain injury-induced impulsive and attentional deficits

Traumatic brain injury (TBI) is defined as damage to the brain that is caused by an external force (Ahmed et al., 2017). It is estimated that nearly 69 million people worldwide sustain a TBI each year (Dewan et al., 2018), and approximately 1-2\% of the United States population are living with TBI-related disability (Thurman, Alverson, Dunn, Guerrero, \& Sniezek, 1999). Brain injury often results in long-term neurological and psychiatric symptoms, such as impulsivity and attention deficits (Ozga, Povroznik, Engler-Chiurazzi, \& Vonder Haar, 2018; Reeves \& Panguluri, 2011). Despite the number of TBI survivors, there are no FDAapproved pharmacological treatments available. However, symptom-specific treatments may be available to manage TBI-induced cognitive impairments. Neuroinflammation can persist years after injury (Ramlackhansingh et al., 2011), and is associated with impulsive symptoms after TBI (Vonder Haar et al., 2016). Thus, chronic neuroinflammation after TBI may be a contributing factor to injury and cognitive impairments, as well as a potential avenue for treatment. One such potential therapeutic, minocycline, is a tetracycline antibiotic that has anti-inflammatory properties (Yong et al., 2004). Additionally, the study of TBI in humans is complicated by the heterogeneity of injuries, which hampers comparisons of drug efficacy and potency. Conversely, preclinical models provide control by limiting both genetic variance and heterogeneity of injury. The current study used a rat model of TBI to examine minocycline as a treatment for TBIinduced impulsivity and attentional deficits. Specifically, this study looked at minocycline in two ways: (1) prevent injury-induced cognitive impairments with early treatment, and (2) recover injury-induced dysfunction with a late intervention. This design allowed for the determination of neuroinflammation as causal to persistent psychiatric deficits or to the development of such impairments. 


\section{Preclinical Models of Brain Injury}

One of the most common models of traumatic brain injury is the controlled cortical impact (CCI). Initially developed by Lighthall (1988) to induce damage in ferrets, it was later adapted to be used in rodents (Dixon, Clifton, Lighthall, Yaghmai, \& Hayes, 1991). The CCI produces focal injuries using an impactor tip that is controlled either pneumatically or electromagnetically. These focal injuries allow for a high level of precision compared to injuries humans typically sustain by having various adjustable parameters such as velocity, depth, and size and shape of the tip. Having reliable injuries also leads to a greater amount of reproducibility. The CCI model is ideal for studying long-term outcomes associated with TBI because it has a high survival rate and progressive pathological changes (Osier \& Dixon, 2016). Evidence from the Vonder Haar Lab shows consistent cognitive impairments and tissue damage up to 12 weeks post-injury (Martens et al., 2019; Shaver et al., 2019). Along with this, other studies find reliable long-term impairments on the Morris Water Maze (MWM) following CCI injury in rats (Cheng et al., 2012; Xiong et al., 2012). In contrast, other injury models such as fluid percussion fail to report steady chronic impairments on the MWM (Hamm, Pike, Temple, O'Dell, \& Lyeth, 1995; Shultz et al., 2012). The bilateral frontal TBI is used to induce focal damage in the prefrontal cortex (Hoffman, Fülöp, \& Stein, 1994). In the current study, a severe bilateral frontal CCI was used to induce TBI.

\section{Cognitive Impairment after Traumatic Brain Injury}

Impaired impulse control is a common complaint of TBI patients and can manifest as verbal or physical actions that result from an inability to inhibit a response (McAllister, 2008). Motor impulsivity often displays as impulsive aggression (quick, aggressive response to minimal stimulus) and is correlated with criminal behaviors after TBI (Alderman, 2003; Dyer, Bell, 
McCann, \& Rauch, 2006). Another consequence of poor impulse control in clinical TBI

populations is hypersexuality or inappropriate sexual behavior (Simpson, Sabaz, \& Daher, 2013).

Both aggressive behavior and unfitting sexual behavior caused by injury-induced impulsivity can reduce quality of life for individuals after brain injury.

Attention deficits are another commonly-reported symptom after TBI (Reeves \& Panguluri, 2011). Inattention can disrupt daily function, and attention impairments after TBI must be addressed. There is strong evidence supporting that TBI increases impulsivity and inattention, yet, no treatments to recover function have been discovered; therefore, there is a strong need to develop effective treatments.

\section{Impulsivity}

Impulsive behavior is defined as an action that has the potential for a short-term gain, but at the cost of long-term benefits (Ozga et al., 2018; Winstanley, Eagle, \& Robbins, 2006). As a complex cognitive construct, it is hard to define and measure impulsivity in a single term; therefore, it can be broken down into two major categories, motor impulsivity, and choice impulsivity. Motor impulsivity is response disinhibition or acting without thinking. Choice impulsivity is often referred to as discounting and the inability to value delayed rewards (Ozga et al., 2018; Winstanley et al., 2006).

Several tasks are used to study motor impulsivity in humans and include: stop-signal, continuous performance, and go/no-go tasks. In the stop-signal and go/no-go tasks, participants respond rapidly to a "go" stimulus, but an occasional "stop" stimulus signals that responding should be inhibited. Damage to the right inferior frontal gyrus impairs performance on the stopsignal task (Aron, Fletcher, Bullmore, Sahakian, \& Robbins, 2003). Patients with brain injuries had lower levels of response inhibition, and their performance significantly dropped when 
distracted with an emotion-driven distractor (Rochat, Beni, Annoni, Vuadens, \& Van der Linden, 2013). The continuous performance task measures motor impulsivity, sustained, and selective attention by having constantly changing stimuli with a target stimulus that signals to respond or to inhibit responding. Both continuous performance task and go/no-go are similar responseinhibitory tasks that find consistent TBI-related impulsivity deficits in clinical studies (Chen et al., 2012; Duncan, Kosmidis, \& Mirsky, 2005; Stephens et al., 2017). However, while substantial clinical data supports a relationship between TBI and impulsivity, animal models must be used to investigate the nuances of this connection to understand the underlying mechanisms.

Typical measures for motor impulsivity in rodents include: Go/no-go, stop-signal task, differential reinforcement of low-rate behavior (DRL), and the five-choice serial reaction time task (5CSRT). These tasks often resemble measurements of motor impulsivity in humans. For instance, go/no-go, and stop-signal tasks use the similar design of having "go" cues that animals learn to respond to and then "stop" cues to which responding must be inhibited (Winstanley et al., 2006). The DRL is a free-operant task that requires a complete stop in responding for a duration of time to receive reinforcement (Ferster \& Skinner, 1957). Several preclinical studies in rodents report TBI-related motor impulsivity deficits on the go/no-go, stop-signal, and DRL (Hehar, Yeates, Kolb, Esser, \& Mychasiuk, 2015; Lindner et al., 1998; Mychasiuk, Hehar, \& Esser, 2015). The 5CSRT simultaneously measures attention, impulsivity, and motivation (Robbins, 2002). Bilateral frontal TBI increased impulsivity and inattention measured by the 5CSRT (Martens et al., 2019; Vonder Haar et al., 2016). Although impulsivity and attention can be studied separately, it is crucial that they are studied together, because the difference between impulsivity and inattention can be subjective. For example, inattention could lead to an impulsive response, whereas impulsivity could bring on poor attention (Winstanley et al., 2006). 
Impulsivity and attention are connected topics and studying these concepts together is best, especially when assessing for treatments because it yields stronger translation into clinical populations.

\section{Attention}

Attention is broadly defined as the action of processing environmental stimuli (Robbins, 2002). Attention has multiple facets but can be broken down into three parts: sustained, divided, or selective attention. Sustained attention is the ability to maintain attention for long durations, whereas divided attention is the ability to process multiple contingencies from sensory inputs and respond accordingly. Selective attention is the capacity to respond to one stimulus in the presence of several different stimuli (Mathias \& Wheaton, 2007; Robbins, 2002). Both sustained and divided attention are impaired in clinical TBI populations (Dockree et al., 2004; Tramontana, Cowan, Zald, Prokop, \& Guillamondegui, 2014; Robertson \& Schmitter-Edgecombe, 2017). Sustained attention deficits make complex tasks difficult and challenge the individual to get through a full day. Subsequently, this could lead to a decrease in performance at work or school and in turn, reduce the quality of life. Consequently, it is vital to develop treatments that can recover TBI-induced attention dysfunction.

There are several tests that measure attention, and since attention is a multifaceted concept, interpretations of the same test may vary. Therefore, it is important to clearly define the type of attention being studied and to use the proper test to assess that variable. Sustained attention is measured using tasks across longer durations. Tests such as the Sequence Sustained Attention Task, Continuous Performance Task, or Attention Network Test measure sustained attention and all show decreased performance after brain injury (Dockree et al., 2004; Tramontana et al., 2014; Lawton \& Huang, 2019). Divided attention is measured with tasks that 
have multiple contingencies (e.g., visual stimulus and audio tones) and attending to both is reinforced. After severe TBI in humans, there is a decrease in divided attention (Robertson \& Schmitter-Edgecombe, 2017; Tramontana et al., 2014). Despite this clinical evidence, preclinical models need to address mechanisms behind TBI-related attention dysfunction to find effective and targeted treatments.

In preclinical measures of attention, the 5CSRT is predominately used and animals with moderate-to-severe injuries display impaired attention (Martens et al., 2019; Vonder Haar et al., 2016). The 5CSRT was adapted from the Continuous Performance Task, a neuropsychological test used to diagnose ADHD (Carli, Robbins, Evenden, \& Everitt, 1983). This task simultaneously measures impulsivity, attention, and motivation, and each aspect can be disassociated from one another. Specifically, the 5CSRT measures motor impulsivity (premature responding) and sustained attention (attending across the whole visual field) both of which are impaired after injury. Bilateral frontal CCIs show consistent deficits in both attention and impulsivity using the 5CSRT (Martens et al., 2019; Vonder Haar et al., 2016). Because of these advantages, for the proposed work, the 5CSRT was used.

\section{Inflammation after Traumatic Brain Injury}

Damage after TBI comes in two forms: primary and secondary injury. Primary injury is damage from the initial insult and occurs at the time of the blow; these injuries consist of neuronal cell death, axonal shearing, cerebral contusion, and hemorrhage (Stein, Brailowsky, \& Will, 1995). Secondary injuries are the indirect results of TBI that start to develop minutes after the initial hit to the head. These secondary injuries are from biochemical, metabolic, and cellular changes from the primary injury and include oxidative stress, blood-brain barrier disruptions, cell death, mitochondrial dysfunction, excitotoxicity, and neuroinflammation (Loane \& Faden, 2010). 
Although primary injuries can be substantial, secondary injuries such as neuroinflammation, propagate damage and persist years post-injury (Loane \& Faden, 2010; Ramlackhansingh et al., 2011). Reducing secondary damage after TBI may decrease chances of lasting behavioral effects. The inflammatory response begins several hours after injury and can last years (Loane \& Kumar, 2016). In TBI populations, increased pro-inflammatory markers have been reported up to 17 years post-injury (Ramlackhansingh et al., 2011). The neuroinflammatory response after injury is complex and involves immune cells from the bloodstream that enter through the disrupted blood-brain barrier, and immune-like cells in the central nervous system (Loane \& Kumar, 2016; Simon et al., 2017). Damage-associated molecular patterns (DAMPS) are proteins, nucleic acids, or other molecules that are present in cells before the injury and are released in response to cellular damage. In contrast, apoptosis, the controlled destruction of cells, does not result in the release of DAMPS (Loane \& Kumar 2016). These DAMPS activate immune responders such as microglia and astrocytes in the central nervous system, and macrophages and neutrophils from peripheral tissues (Wofford, Loane, \& Cullen, 2019). Once these immune cells accumulate around the injury, they start to clear debris via phagocytosis; however, as they clean, they also release toxic substances such as reactive oxygen species, chemokines, and cytokines that can augment cellular damage and prolong neuroinflammation (Donat, Scott, Gentleman, \& Sastre, 2017; Loane \& Kumar, 2016). Ischemic strokes have a similar response in that microglia are the first responders to injury then infiltrating peripheral immune cells follow (Ma et al., 2017). In the context of ischemic stroke, microglia cells become activated within minutes of the ischemic event and can produce inflammatory mediators such as nitric oxide synthase, nitric oxide, and pro- and anti-inflammatory cytokines (Ma et al., 2017). 
Microglia play a significant role in the neuroinflammatory response after brain injury (Donat et al., 2017; Loane \& Kumar, 2016). Microglia exist along a spectrum of proinflammatory and anti-inflammatory processes but can be dichotomized to an M1-like (proinflammatory) and M2-like (anti-inflammatory) phenotype (Kumar, Alvarez-Croda, Stoica, Faden, \& Loane, 2016). In the M1-like state, microglia typically exhibit pro-inflammatory processes, and they will signal and produce pro-inflammatory cytokines such as tumor necrosis factor-alpha (TNF- $\alpha$ ), interleukin (IL) 1-beta, and IL-6. The M1-like state is related to chronic neuroinflammation, oxidative stress, and neuronal destruction through phagocytosis (Xu et al., 2017). Conversely, microglia in the M2-like state exhibit anti-inflammatory characteristics. M2like microglia typically increase neurotrophic factors, clear cell debris without changing morphology, and release anti-inflammatory cytokines such as IL-4 and IL-10 (Song \& Suk, 2017). After TBI, microglia exist in both M1-like and M2-like states. However, the M2-like levels peak within five days post-injury and then the M1-like state dominates, promoting a prolonged pro-inflammatory response (Jin, Ishii, Bai, Itokazu, \& Yamashita, 2012). In ischemic stroke, microglia have a similar response to injury and exist in both the pro- and antiinflammatory states. Initially after ischemic stroke, microglia will exhibit M1-like characteristics such as increased levels of cluster of differentiation (CD) CD11b, CD16, CD32, and CD86 but not starting until day 3 after injury (Hu et al., 2012). M2-like microglia after stroke are associated with increases in expression of IL-10 and TGF- $\beta$. These anti-inflammatory microglia levels begin to increase within the first day after injury, but peak by day 5 post-stroke (Hu et al., 2012). Due to these dynamic processes of microglia, it is essential to consider the time-dependent nature of manipulating microglia after brain injury. 
Neuroinflammation is a common form of secondary injury and can last years after the initial injury (Ramlackhansingh et al., 2011). Cognitive symptoms such as impulsivity and attention deficits have been reported as chronic effects after brain injury (Dockree et al., 2004; Rochat et al., 2013). Psychiatric disorders that have characteristics of impulsiveness and inattention, such as Attention-Deficit/ Hyperactivity Disorder have been linked with increased inflammatory cytokine markers (Mitchell \& Goldstein, 2014). Specifically, increased IL-6 was associated with impulsivity, and inattention was associated with increased IL-13 (Oades, Myint, Dauvermann, Schimmelmann, \& Schwarz, 2010). The long-term cognitive deficits seen in TBI may be exacerbated by prolonged neuroinflammation; thus, treatments that target the inflammatory response should be explored.

\section{Minocycline}

Minocycline is a broad-spectrum antibiotic that is typically used to treat acne and sexually transmitted infections (Garrido-Mesa, Zarzuelo, \& Gálvez, 2013). Minocycline is a lipophilic molecule and can easily pass through the blood-brain barrier, making it available for CNS interventions (Garrido-Mesa et al., 2013; Yong et al., 2004). It has neuroprotective properties related to microglia deactivation (Henry et al., 2008; Yong et al., 2004). In the central nervous system, minocycline can reduce neuroinflammation, decrease cell-death, and promote neurotrophic factors (Yong et al., 2004). Minocycline can inhibit microglia, both directly and indirectly. Direct inhibition of microglia by minocycline occurs through reducing the expression of toll-like receptor (TLR) 2 and TLR4 on microglia cells (Henry et al., 2008; Zhao, Zhang, \& Li 2015). These TLRs recognize DAMPs or other foreign substances and activate an innate immune response; specifically, TRL4 activation leads to the synthesis of pro-inflammatory cytokines and chemokines (Vaure \& Liu, 2014). Minocycline reduces pro-inflammatory signalers such as 
caspase I, nitric oxide synthase, and genes for IL-6, TNF- $\alpha$, IFN- $\gamma$, and IL- $1 \beta$, thus, decreasing the inflammatory response (Henry et al., 2008; O'connor et al., 2009). In vitro, minocycline reduced the pro-inflammatory effects of LPS by decreasing the expression of p38 and MMP9 and reducing IL-6 and IL-1 $\beta$ production by microglia (Piotrowska, Popiolek-Barczyk, Pavone, \& Mika, 2017). In vitro, astrocytes demonstrated a response like that of the microglia reducing expression of p39 and MMP9 as well as pro-inflammatory signals (Piotrowska et al., 2017). Due to astrocytic reliance of microglia post-injury neuroinflammation, microglia were the primary interest for this work. Therefore, I hypothesized that reducing the microglial pro-inflammatory response may decrease long-term dysfunction after TBI.

In some rat models of TBI, minocycline attenuates injury-related deficits such as cognitive impairments, lesion size, and microglia levels. Minocycline treatment recovered spatial learning and memory dysfunction measured by Morris water maze and the Barnes maze (Kovesdi et al., 2012; Kumar, Rinwa, \& Dhar, 2014; Lam et al., 2013; Sangobowale et al., 2018; Simon et al., 2018). Minocycline also reduced the number of microglia present and decreased lesion size (Adembri et al., 2014; Haber et al., 2018; Hanlon, Raghupathis, \& Huh, 2017). However, these therapeutic effects depended on the dose. At $45 \mathrm{mg} / \mathrm{kg}$, minocycline can reduce lesion size and decrease microglia after injury (Adembri et al., 2014; Haber et al., 2018; Hanlon et al., 2017). Similarly, at higher doses of $50 \mathrm{mg} / \mathrm{kg}, 60 \mathrm{mg} / \mathrm{kg}$, and $90 \mathrm{mg} / \mathrm{kg}$ there was functional recovery and decreased pathology of inflammatory markers such as microglia and pro-inflammatory cytokines (Kovesdi et al., 2012; Kumar et al., 2014; Simon et al., 2018; Vonder Haar et al., 2014). At doses lower than $45 \mathrm{mg} / \mathrm{kg}$, the effect of minocycline was more variable in recovering behavioral deficits or decreasing lesion size or microglia levels (Lam et al., 2013; Kelso, Scheff, Scheff, \& Pauly, 2011; Sangobowale et al., 2018). The effectiveness of 
the dose also depended on the severity of injury and most behavioral recovery was seen when the injury was moderate-to-severe. The current study used a severe injury and $45 \mathrm{mg} / \mathrm{kg}$ of minocycline based on the previous work reviewed above. Minocycline was an effective treatment starting at various time points post-injury, including: immediate, $10 \mathrm{~min}, 30 \mathrm{~min}, 1 \mathrm{~h}, 2$ h, 4 h, 6 h, 12 h, 24 h, and 15 d (Adembri et al. 2014; Haber et al., 2018; Kovesdi et al. 2012; Kumar et al., 2014; Lam et al. 2013; Sangobowale et al., 2018; Simon et al., 2018; Vonder Haar et al. 2014). We started an early round of treatment at $1 \mathrm{~h}$ post-injury before neuroinflammation fully progresses. In humans, the half-life of minocycline ranges $15-24 \mathrm{~h}$ hours; however, in rodents, the half-life is about 2-3 h (Yong et al., 2004). Although minocycline has a short halflife in rodents, we dosed every $12 \mathrm{~h}$ because this still dampened the pro-inflammatory microglial response after brain injury and had been effective in multiple previous studies. For a summary of minocycline rat studies see Table 1 .

Preclinical data is promising for the use of minocycline as a treatment for TBI, yet, limited clinical work has been done. Treatments of minocycline six months after moderate-tosevere injury reduced microglial activation (Scott et al., 2018). These treatments also increased neurofilament light chain (a measure of active neurodegeneration) after 12 weeks of taking the drug, but this attenuated after 6 months of treatment (Scott et al., 2018). Another study found large doses of minocycline to be safe after TBI (Meythaler et al., 2019). These two clinical studies show minocycline as a promising potential treatment for TBI-related deficits. However, clinical trials often fail due to accelerated testing of novel drugs that lack proper validation. Thus, it is important to refine and continue preclinical studies.

\begin{tabular}{|l|l|c|c|c|c|c|}
\hline Authors & \multicolumn{1}{|c|}{$\begin{array}{c}\text { Injury } \\
\text { Severity }\end{array}$} & Dose & Time & $\begin{array}{l}\text { Cognitive } \\
\text { Behavior }\end{array}$ & $\begin{array}{c}\text { Microglia } \\
\text { Levels }\end{array}$ & Lesion \\
\hline $\begin{array}{l}\text { Haber et al., } \\
2018\end{array}$ & Mild & $45 \mathrm{mg} / \mathrm{kg}$ & $\begin{array}{l}1 \mathrm{~h} \text { post- } \\
\text { injury every } \\
24 \mathrm{~h}\end{array}$ & $\mathbf{\downarrow}$ & \\
\hline
\end{tabular}




\begin{tabular}{|c|c|c|c|c|c|c|}
\hline $\begin{array}{l}\text { Hanlon, Huh, \& } \\
\text { Raghupathi, } \\
2016\end{array}$ & Mild & $45 \mathrm{mg} / \mathrm{kg}$ & $\begin{array}{l}0 \mathrm{~h} \text { post- } \\
\text { injury every } \\
12 \mathrm{~h}\end{array}$ & & & \\
\hline $\begin{array}{l}\text { Hanlon, } \\
\text { Raghupathis, \& } \\
\text { Huh, } 2017\end{array}$ & Mild & $45 \mathrm{mg} / \mathrm{kg}$ & $\begin{array}{l}0 \mathrm{~h} \text { post- } \\
\text { injury every } \\
12 \mathrm{~h}\end{array}$ & & $\underset{(10 \mathrm{~d})(15 \mathrm{~d})}{\downarrow}$ & \\
\hline $\begin{array}{l}\text { Kovesdi et al. } \\
2012\end{array}$ & Mild & $50 \mathrm{mg} / \mathrm{kg}$ & $\begin{array}{l}4 \mathrm{~h} \text { post- } \\
\text { injury every } \\
24 \mathrm{~h}\end{array}$ & \begin{tabular}{l}
\multicolumn{1}{c}{4} \\
marnes
\end{tabular} & & \\
\hline $\begin{array}{l}\text { Kumar, Rinwa, } \\
\& \text { Dhar, } 2014\end{array}$ & Mild & $25 \mathrm{mg} / \mathrm{kg}$ & $\begin{array}{l}15 \mathrm{~d} \text { post- } \\
\text { injury every } \\
24 \mathrm{~h}\end{array}$ & & & \\
\hline $\begin{array}{l}\text { Kumar, Rinwa, } \\
\& \text { Dhar, } 2014\end{array}$ & Mild & $50 \mathrm{mg} / \mathrm{kg}$ & $\begin{array}{l}15 \mathrm{~d} \text { post- } \\
\text { injury every } \\
24 \mathrm{~h}\end{array}$ & $\underset{(M W M)}{\mathbf{4}}$ & & \\
\hline $\begin{array}{l}\text { Adembri et al., } \\
2014\end{array}$ & $\begin{array}{l}\text { Moderate - } \\
\text { severe }\end{array}$ & $45 \mathrm{mg} / \mathrm{kg}$ & $\begin{array}{l}30 \mathrm{~m} \text { post- } \\
\text { injury then } \\
\text { every } 12 \mathrm{~h}\end{array}$ & & & \\
\hline Lam et al., 2013 & $\begin{array}{l}\text { Moderate- } \\
\text { severe }\end{array}$ & $25 \mathrm{mg} / \mathrm{kg}$ & $\begin{array}{l}24 \mathrm{~h} \text { post- } \\
\text { injury every } \\
24 \mathrm{~h}\end{array}$ & $\underset{(M W M)}{\mathbf{A}}$ & & \\
\hline $\begin{array}{l}\text { Sangobowale et } \\
\text { al., } 2018\end{array}$ & Moderate & $22.5 \mathrm{mg} / \mathrm{kg}$ & $\begin{array}{l}6,12, \text { or } 24 \\
h \text { then every } \\
24 \mathrm{~h}\end{array}$ & \begin{tabular}{l}
\multicolumn{1}{c}{$\mathbf{4}$} \\
marnes
\end{tabular} & & \\
\hline $\begin{array}{l}\text { Simon et al., } \\
2018\end{array}$ & $\begin{array}{l}\text { Moderate- } \\
\text { severe }\end{array}$ & $90 \mathrm{mg} / \mathrm{kg}$ & $\begin{array}{l}10 \min \& 20 \\
\mathrm{~h} \text { post-injury }\end{array}$ & $\mathbf{A}_{(\mathrm{MWM})}$ & & \\
\hline $\begin{array}{l}\text { Vonder Haar et } \\
\text { al., } 2014\end{array}$ & $\begin{array}{l}\text { Moderate- } \\
\text { severe }\end{array}$ & $60 \mathrm{mg} / \mathrm{kg}$ & $\begin{array}{l}2 \mathrm{~h} \text { post- } \\
\text { injury then } \\
\text { Every } 12 \mathrm{~h} \\
\text { for } 72 \mathrm{~h}\end{array}$ & & & \\
\hline $\begin{array}{l}\text { Kelso, Scheff, } \\
\text { Scheff, \& Pauly } \\
2011\end{array}$ & Severe & $40 \mathrm{mg} / \mathrm{kg}$ & $\begin{array}{l}24 \mathrm{~h} \text { post- } \\
\text { injury every } \\
24 \mathrm{~h} \\
\end{array}$ & & & \\
\hline
\end{tabular}

Table 1. Minocycline in rat models of TBI, and its effects on behavior, microglia, and lesions. Arrows indicate increase or decrease; flat line represents no effect.

\section{The Current Study}

The current work used minocycline to treat impulsivity and inattention after TBI. This was the first time an anti-inflammatory treatment was used to alleviate impulsivity- and 
attention-related impairments. The 5CSRT was used to measure motor impulsivity and attention. The different treatment interventions of minocycline began at $1 \mathrm{~h}$ and 8 weeks post-injury. Postinjury behavioral testing on the 5CSRT stabilized at 7 weeks post-injury; therefore, the late minocycline treatment began at 8 weeks after injury. The early treatment tested whether dysfunction could be prevented by minocycline whereas the late intervention at 8 weeks after injury examined if minocycline could attenuate such deficits. I hypothesized that minocycline treatment would reduce motor impulsivity at the 8-week time point and prevent an increase of impulsivity, relative to sham levels, at the early dose. I also hypothesized that attention deficits would be recovered with minocycline at the 8-week time and the initial dose would prevent worsening relative to shams. Lastly, I hypothesized that minocycline would reduce brain microglia numbers, as compared to untreated rats subjected to CCI and would decrease the lesion size in the early dose group.

\section{Methods}

\section{Subjects}

Subjects were male, Long-Evans rats $(\mathrm{N}=35)$ approximately 250 - 275g, obtained from Charles River Laboratories. Rats were kept in Optirat cages (Animal Care Systems, Centennial, $\mathrm{CO})$ with corncob bedding and crinkle paper. These rats were triple-housed until surgery, then moved to pair-housing, separated by a divider, after surgery. Environmental conditions were controlled, and rats were kept in an AAALAC accredited vivarium on a $12 \mathrm{~h}$ light/dark reverse cycle. Rats had free access to water and were maintained at $85 \%$ of their free-feeding weight using standard chow receiving $14 \mathrm{~g}$ of food per day. All work was approved by the West Virginia University Institutional Animal Care and Use Committee.

\section{Apparatus}


Testing took place in 16 standard five-hole operant chambers (Med Associates, St. Albans, VT). The chambers were located in sound-attenuating boxes, and white noise machines (about $70 \mathrm{~dB}$ ) were used to ensure background noise was minimized. The chambers had a stainless-steel grid floor and contain two extendable levers, five nose-poke holes with infrared sensors, and a food hopper. The food hopper was between the two levers, and the five nose-poke holes were located on the opposite side of the chamber. Above the levers and in the nose-poke holes were stimulus lights, and above the food hopper was a house light. The chambers were also equipped with a tone generator that were not used in this study. Only the five nose-poke holes with stimulus lights and food hopper were used in this study. Sucrose pellets (45 mg, BioServ, Fleming, NJ) were used as reinforcers. Custom software written in Med-PC IV controlled the chambers.

\section{Behavioral Testing - the 5-choice serial reaction time task}

The 5CSRT measures impulsivity and attention. Trials were initiated with a nose poke into the food hopper and a $5 \mathrm{~s}$ inter-trial interval (ITI) began, in which rats had to inhibit responding. Responses during the ITI (i.e., a premature response) were punished with a $5 \mathrm{~s}$ timeout. After the ITI, a stimulus light in one of five of the holes illuminated for $0.5 \mathrm{~s}$ and responding correctly (nose poke to illuminated hole) within the $5 \mathrm{~s}$ limited hold was reinforced. Failure to respond within the limited hold (i.e., omission) was punished with a $5 \mathrm{~s}$ timeout, and an incorrect response (i.e., nose poke to wrong hole) was punished with a $5 \mathrm{~s}$ timeout. Each session lasted for 30 minutes and had a maximum of 100 trials (see Figure 1). The main variables of interest included premature responses (impulsivity), correct and incorrect responses (attention), omissions, task efficacy index (correct/(incorrect + premature + omissions). 


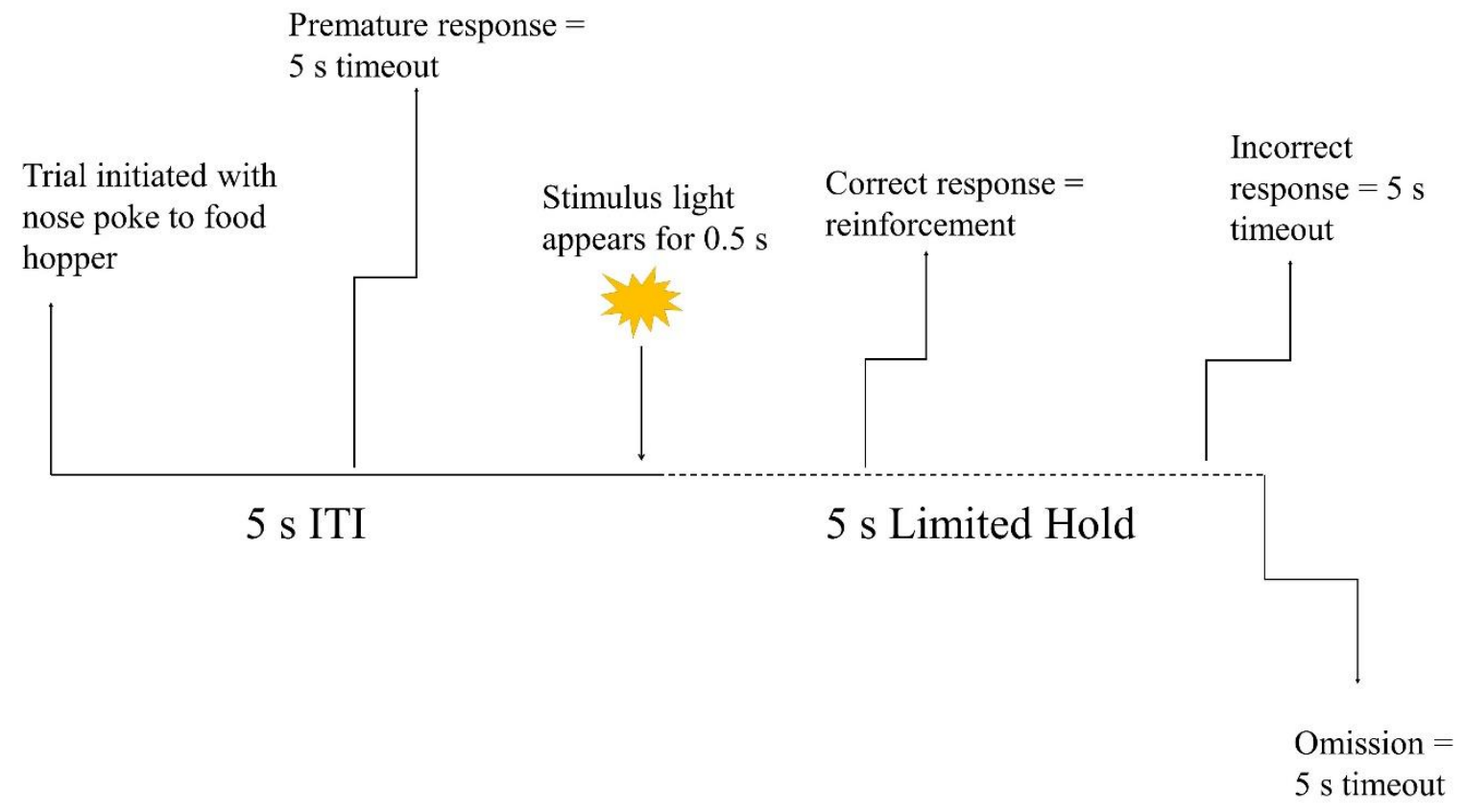

Figure 1. Diagram of 5-choice serial reaction time task; adapted from Robbins, 2002.

\section{Behavior Training}

Behavioral training was adapted from prior publications (Carli et al., 1983; Vonder Haar et al., 2016). To reduce neophobia, sucrose pellets were placed in the housing cages one day before behavioral training began. First, rats were habituated to the operant chambers by placing 5 sucrose pellets into each of the five nose poke holes and 10 pellets into the food hopper. After consuming all of the sucrose pellets within $30 \mathrm{~min}$, rats moved on to the 5-choice training sessions. The 5-choice training stages included 12 stages that had varying ITI, stimulus durations, and limited holds (LH). Stage 1 started with a $2 \mathrm{~s}$ ITI and $30 \mathrm{~s}$ stimulus duration and $30 \mathrm{~s} \mathrm{LH}$. As the stages progressed, the ITI, stimulus durations, and LH gradually got closer to the full task of ( $5 \mathrm{~s}$ ITI, $0.5 \mathrm{~s}$ stimulus duration, and $5 \mathrm{~s} \mathrm{LH})$. A training session lasted for $30 \mathrm{~min}$ and rats moved on to the next stage after criteria for their current stage was met (e.g., 30 correct responses; see appendices for more details). Stability criteria was defined as a consistent number 
of correct, incorrect, premature, and omission data for five days, which took approximately 65 sessions.

\section{Surgery}

Rats were pair-matched based on premature and attention baseline data on the 5CSRT then assigned to receive a TBI $(n=23)$ or sham injury $(n=12)$. Rats received a severe bilateral frontal controlled cortical impact TBI (Hoffman et al., 1994). First, rats were anesthetized with isoflurane (5\% induction, $2-4 \%$ maintenance) in $0.5 \mathrm{~L} / \mathrm{min}$ oxygen. Rats were placed on a stereotaxic frame, local analgesic (bupivacaine, $0.1 \mathrm{~mL}$ of $0.25 \%$ solution) was administered at the incision site, and general analgesic given subcutaneously (ketoprofen, $5 \mathrm{mg} / \mathrm{kg}$ ). Next, the incision site was sterilized, a midline incision performed, and retractors were placed. A 6 mm diameter circular craniotomy was completed at $3 \mathrm{~mm}$ anterior to bregma, centered on the midline. A Leica Impact One device (Leica Biosystems, Buffalo Grove, IL) was used to induce a bilateral TBI with a consistent depth $(-2.5 \mathrm{~mm})$, velocity $(3 \mathrm{~m} / \mathrm{s})$, and dwell $(500 \mathrm{~ms})$. Sterile gauze was used to stop bleeding after the impact, and then the incision site was sutured. Triple antibiotic ointment was put on the incision site to prevent infection. Sham surgeries were identical to TBI but excluded the impact.

\section{Treatment/Treatment Groups}

Minocycline hydrochloride (Cayman Chemical, Ann Arbor, MI) 45 mg/kg given in a 12 $\mathrm{mg} / \mathrm{ml}$ solution or vehicle (saline volume matched based on body weight) was delivered via intraperitoneal route. One group started treatment $1 \mathrm{~h}$ post-injury (MINO-Early) and the other received drug at 8 weeks post-injury (MINO-Late). Minocycline or vehicle was administered twice daily every $12 \mathrm{~h}$ for 5 days. There were 6 groups including: Sham-VEH ( $\mathrm{n}=5)$, Sham- 
MINO-Early (n=7), TBI-VEH (n=7), TBI-MINO-Early (n=7), TBI-MINO-Late (n=9) (see table 2). Minocycline had no effect on behavior in the early dose (accuracy: $t(54.353)=1.3369, p=$ 0.187; premature: $t(60.307)=-1.1096, p=0.2716)$. Therefore, the Sham-MINO-Early and Sham-VEH groups received the same manipulation (minocycline or vehicle) during the late time point.

\begin{tabular}{|l|l|l|l|}
\hline & VEH & MINO-Early & MINO-Late \\
\hline Sham & 5 & 7 & -- \\
\hline TBI & 7 & 7 & 9 \\
\hline
\end{tabular}

Table 2. Groups.

\section{Behavioral Assessment}

Rats had 7 days of post-surgery recovery before they resume testing on the 5CSRT. Rats were tested 12 weeks post-injury, that is, 4 weeks after the late round of minocycline treatment concluded.

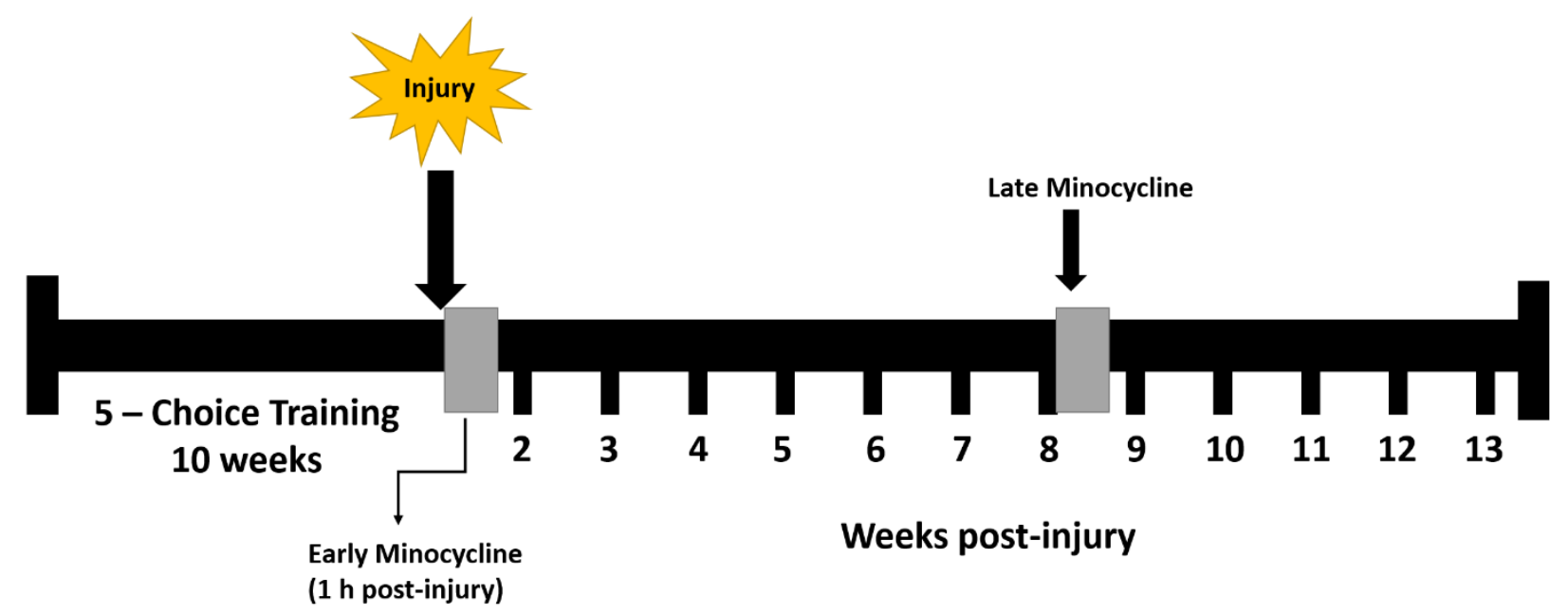

Figure 2. Timeline of the study design.

\section{Histology}


Upon completion of behavioral testing (12 weeks after injury), rats were transcardially perfused with $0.9 \%$ phosphate buffered saline, followed by $3.7 \%$ phosphate buffered formaldehyde. Brains were fixed in $3.7 \%$ formaldehyde for $24 \mathrm{~h}$ then placed in $30 \%$ sucrose. After 3 days in sucrose, brains were embedded into $15 \%$ gelatin with 4 or 3 brains per matrix. Blocks were frozen and sliced into $30 \mu \mathrm{m}$ coronal sections with a sliding microtome (Shaver et al., 2019).

Microglia were assessed using a chromogenic IBA-1 stain (Ito et al., 1998). Slices were incubated in $2 \%$ normal goat serum for $4-24 \mathrm{~h}$ at $4^{\circ} \mathrm{C}$ then left in the IBA-1 primary antibody (1:2000; WAKO 019-19741) for $48 \mathrm{~h}$ at $4^{\circ} \mathrm{C}$. The secondary antibody was goat anti-Rabbit IgG (1:2000; vector BA-100) and was incubated for $90 \mathrm{~min}$ at $23^{\circ} \mathrm{C}$ (room temperature). A Vectastain ABC kit (Vector Laboratories) was used following the secondary. Last, for visualization, 3-3'- diaminobenzidine (DAB; Vector Laboratories) peroxide solution was used (0.05\% DAB \& $0.015 \% \mathrm{H}_{2} \mathrm{O}_{2}$ in PBS). Stains were mounted on slides, dehydrated, then cover slipped. Images of the brains were taken at 40x magnification using an Olympus BX43 microscope with DP-80 13.5 megaplixel camera in CellSens software. ImageJ (NIH, Bethesda, MD) was used to analyze microglia count in three regions of interest: orbitofrontal cortex, prelimbic area, and hippocampus. Microglia cells were counted by hand and averaged across regions and groups. The orbitofrontal cortex (OFC) was assessed due to its involvement in the 5CSRT, specifically important for the impulsivity aspect (Robbins, 2002). The prelimbic area (PrL) is also implicated in 5CSRT performance but the attentional aspect instead of impulsivity and was chosen for that reason (Robbins, 2002). The OFC and PrL are located near the lesion but remained intact which made them ideal regions to assess for interactive effects of injury, minocycline, and performance on 5CSRT. The hippocampus (HPC) served as the control for the 
effects of tissue damage on inflammation since it is distal to the frontal lesion and is relatively unaffected by the frontal CCI injury.

A lesion analysis was completed to assess injury size. Slices were stained with thionin solution to visualize lesions, so they could be measured. Thionin staining protocol consisted of rehydrating cells with ethanol solutions, a brief submerge in thionin solution $(<20 \mathrm{~s})$, and ended with dehydration in ethanol solutions. Immediately after the dehydration, slides were cover slipped. After the glue dried, images of the slides were captured using a Konica Minolta copier at $600 \mathrm{DPI}$ and then brain volume was measured using ImageJ (NIH, Bethesda, MD). Brain volume was calculated by averaging the area of five regions $(+4.5,+3.5,+2.5,+1.5,+0.5$ from bregma) then multiplying by thickness (5um) (Vonder Haar et al., 2017).

\section{Data Analysis}

For all data analysis, the MINO-Early and MINO-Late groups were analyzed separately. A linear regression (Injury x Drug x Week) with baseline added as a covariate was used to determine the effects of treatment and injury on the 5CSRT variables. For the 5CSRT, the primary outcome variables were percent accuracy (correct/ (correct + incorrect)), percent premature responses (premature/total trials), percent omissions (omissions/total trials), and task efficacy index (correct/ (incorrect + premature + omissions)). Log transformations were performed on premature, omission, and task efficacy index to normalize data before the regression was completed, and an arcsine square root transformation was performed on accuracy. In the MINO-Late group, two regressions were completed for each variable. One regression was to verify the initial effect of injury (1-7 weeks post-injury) and the second to measure potential effects of minocycline, with week 7 post-injury serving as the baseline. Microglia were analyzed via IBA-1 positive cell counts and a two-way ANOVA (Injury x Drug) was completed. A two- 
way ANOVA (Injury x Drug) was used for the lesion analysis. All data analysis was completed using RStudio statistical software (version 4.0.2) and libraries plyr, plotrix, lmer, and lmerTest.

\section{Results}

The major findings from behavioral testing and histology are provided below, but expanded statistics, including null findings and beta coefficients, can be found in tables (see Appendices). All beta coefficients were standardized.

\section{Early: Behavior}

Premature. TBI increased premature responding $(p=0.001)$. Minocycline did not decrease the number of premature responses differentially in either group $(p=0.419)$. But, did have an overall effect of slope in that rats that received minocycline recovered faster compared to saline rats $(p<0.001$; Table 2; Figure 3A).

Accuracy. TBI decreased accuracy $(p=0.001)$ and while both groups recovered over time, the TBI rats had a slower rate of recovery ( $p=0.025$; Table 3; Figure 3B). Minocycline did not improve accuracy in TBI rats $(p=0.854)$ but did lead to an overall increase in accurate responding over time ( $p=0.023$; Table 3: Figure 3B).

Omissions. TBI increased omissions initially $(p<0.001)$ but there was an overall decline in omissions across time $(p<0.001)$. Minocycline did not decrease omissions after TBI $(p=$ 0.558; Table 4; Figure 3C).

Task Efficacy Index. TBI decreased the overall efficacy on the task $(p=0.001)$. Minocycline did not increase overall task performance after injury $(p=0.817)$ but did increase the rate of improvement on the task over time compared to rats that were given saline $(p=0.028$; Table 5; Figure 3D). 

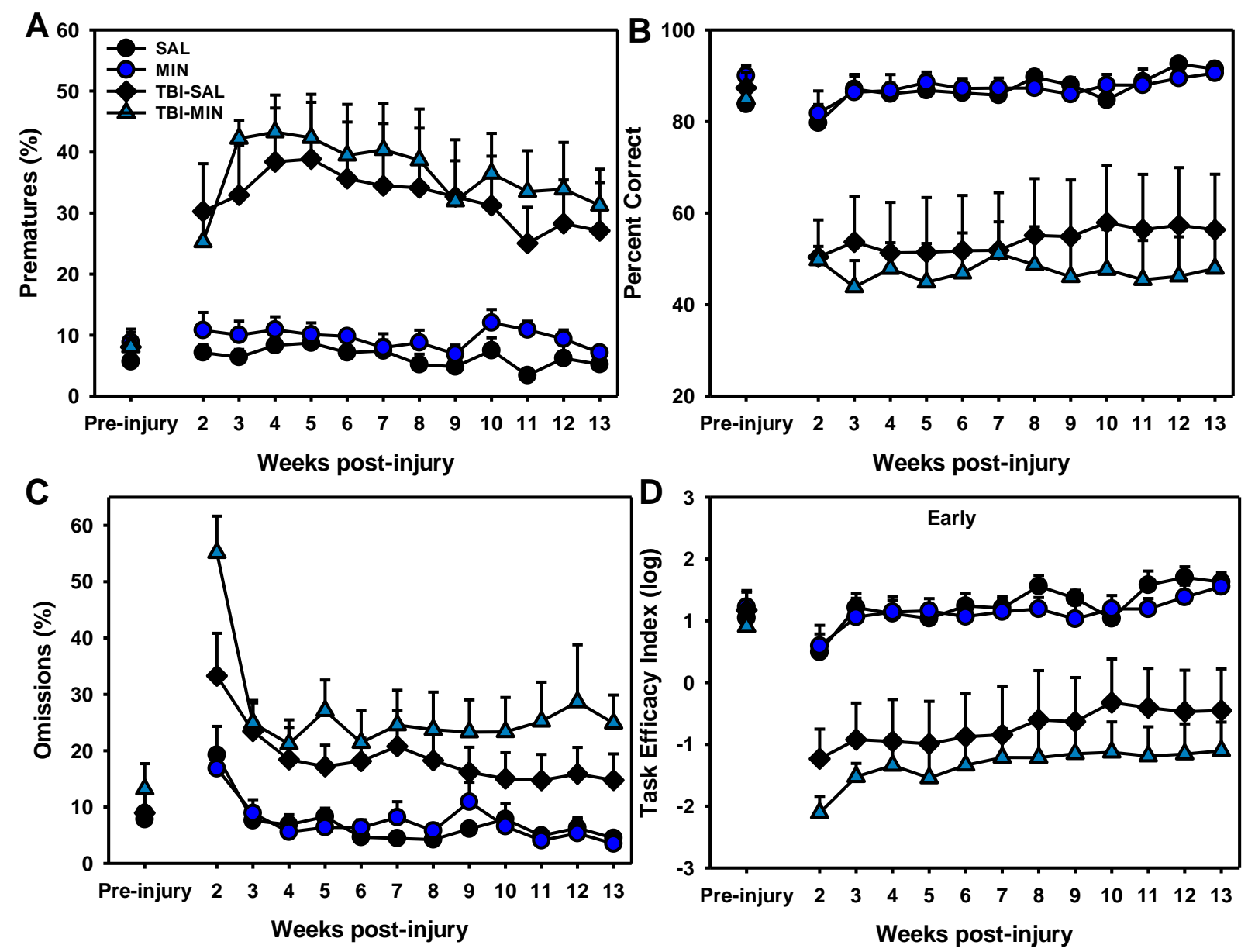

Figure 3. The effects of minocycline on premature responses (A), accuracy (B), omissions (C), and index (D) on the 5CSRT. TBI increased impulsivity, inattention, and omissions and minocycline did not recover these deficits $(p=0.001 ; p=0.001 ; p<0.001 ; p=$ $0.926 ; p=0.854 ; p=0.558)$. Minocycline decreased the recovery rate of TBI and sham rats in premature responding and accuracy $(p<0.001 ; p=0.023)$.

\section{Early: Histology}

Lesion Analysis. TBI rats had smaller brain volumes and larger lesions compared to shams $(F(1,22)=8.328, p=0.009 ; F(1,22)=15.705, p<0.001)$. Minocycline did not decrease 
brain volume or lesion size $((F(1,22)=0.283, p=0.600 ; F(1,22)=1.485, p=0.236)$. Likewise, in TBI rats minocycline did not impact brain volume or lesion size $(F(1,22)=0.042, p=0.834$; $F(1,22)=0.469, p=0.501 ;$ Figure 4$)$.

A

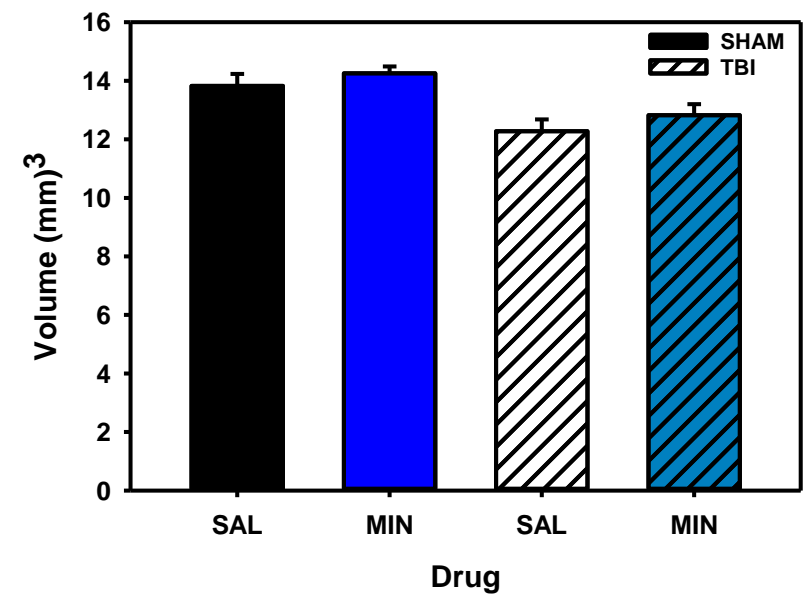

B

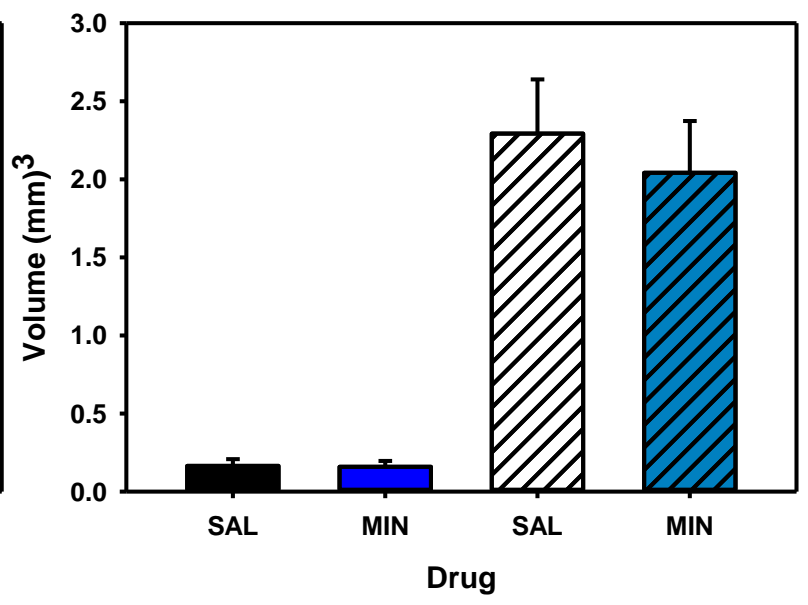

Figure 4. A) Brain volume and B) lesion volume. TBI decreased brain volume and increased lesion size $(p=0.008 ; p<0.001)$. Minocycline did not affect post-injury brain volume or lesion size $(p=0.834 ; p=0.501)$.

Microglia. TBI did not increase number of microglia in the $\mathrm{OFC}, \operatorname{PrL}$, or $\operatorname{HPC}(F(1,22)=$ $2.502, p=0.128 ; F(1,22)=0.110, p=0.743 ; F(1,21)=0.125, p=0.693)$. In the HPC minocycline decreased microglia compared to vehicle rats $(F(1,21)=13.664, p<0.001$; Figure 5C), but this effect was not seen in the $\mathrm{OFC}$ or $\operatorname{PrL}(F(1,22)=1.139, p=0.297 ; F(1,22)=$ 0.610, $p=0.443)$. In TBI rats, minocycline did not affect microglia levels in the OFC, PrL, or $\operatorname{HPC}(F(1,22)=0.000, p=0.991 ; F(1,22)=2.771, p=0.110 ; F(1,21)=0.465, p=0.503$ Figure 5). 

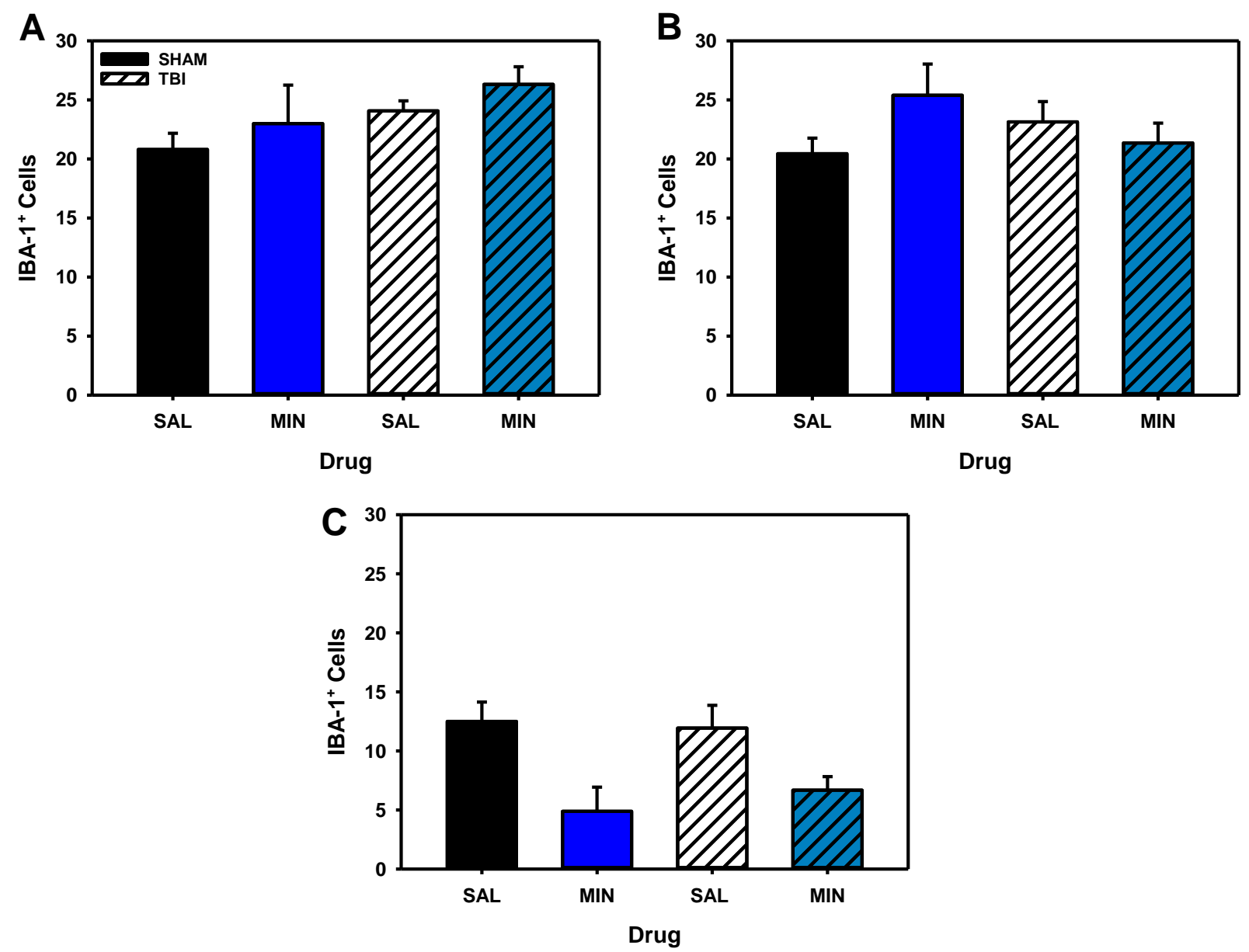

Figure 5. Number of microglia in A) OFC B) PrL C) HPC. TBI did not increase microglia in the OFC, PrL, or HPC ( $p=0.110 ; p=0.743, p=0.723)$. Minocycline did not affect microglia levels in the OFC or PrL $(p=0.298 ; p=0.443)$, but decreased microglia in the HPC compared to vehicle rats $(p<0.001)$.

\section{Late: Behavior}

Premature. TBI increased impulsivity prior to the week 8 minocycline treatment $(p<$ 0.001; Table 2). TBI rats had a slight decline from their seven-week baseline $(p=0.027)$, although the TBI rats remained stable, the sham rats had a slight increase in impulsive 
responding $(p=0.001)$. The late intervention of minocycline at did not attenuate impulsive behavior $(p=0.220$; Table 2; Figure 6A).

Accuracy. TBI increased inattention prior to the late treatment of minocycline at 8 weeks post injury $(p<0.001$; Table 3$)$. Minocycline did not decrease inattention related to the TBI $(p=$ 0.351; Table 3; Figure 6B). There was an increase in inattention in sham rats but not minocycline rats after the minocycline treatment, but levels decreased across time $(p=0.022 ; p=0.050$; Table 3; Figure 6B).

Omissions. TBI increased omissions for the first 7 weeks post-injury $(p<0.001$; Table 4). Minocycline did not attenuate effects of omissions in TBI rats $(p=0.075$; Table 4, Figure 6C).

Task Efficacy Index. Overall performance on the task was decreased after TBI for the first 7 weeks after injury $(p<0.001$; Table 5). Minocycline treatments beginning at 8 weeks post-injury did not improve the task efficacy ( $p=0.510$; Table 5; Figure 6D). 

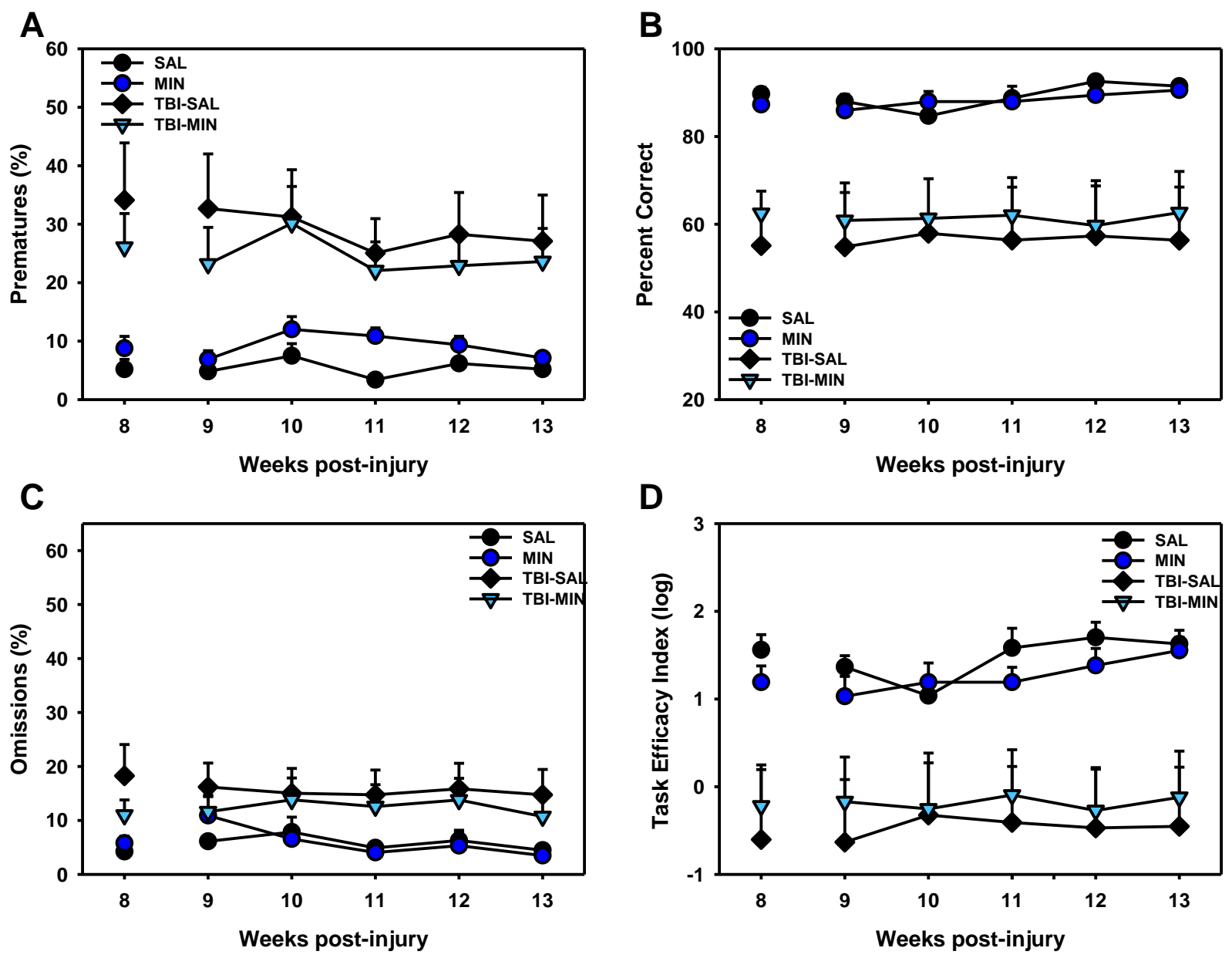

Figure 6. The effects of minocycline on premature responses (A), accuracy (B), omissions (C), and index (D) on the 5CSRT. Minocycline at 8 weeks post-injury did not attenuate impulsivity, inattention, omissions, or overall performance on task $(p=0.220 ; p=$ $0.351 ; p=0.075 ; p=510)$.

\section{Late: Histology}

Lesion Analysis. TBI decreased brain volume and increased lesion volume when compared to shams $(F(1,24)=6.016, p=0.022 ; F(1,24)=9.448 p=0.005$; Figure 7A). Minocycline did not change brain volume or lesion volume compared to saline rats $(F(1,24)=$ $0.001, p=0.974 ; F(1,24)=0.234 p=0.632)$. Brain volume or lesion size was not affected by 
minocycline in TBI rats at eight weeks post-injury $(F(1,24)=0.499, p=0.487 ; F(1,24)=0.002$, $p=0.963 ;$ Figure 7).
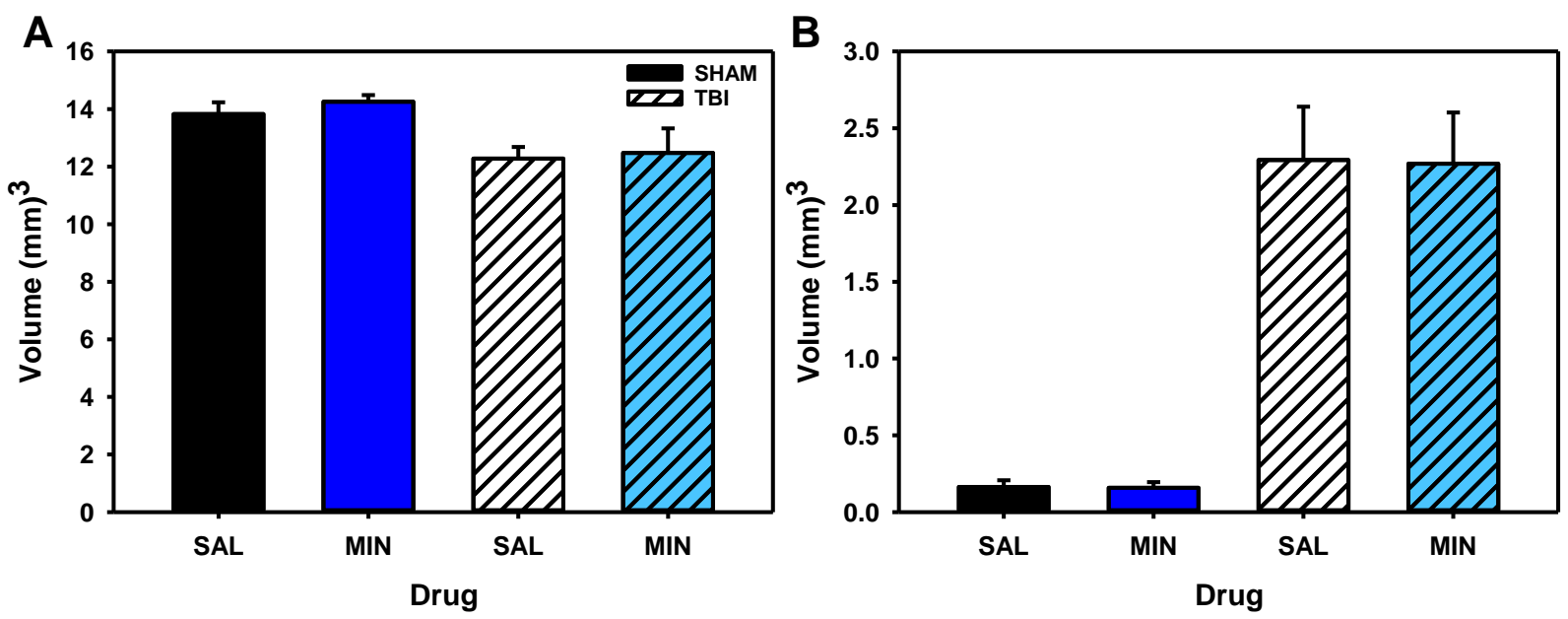

Figure 7. A) Brain volume and B) lesion volume. TBI decreased brain volume and increased lesion size $(p=0.022 ; p=0.005)$. Minocycline did not affect post-injury brain volume or lesion size $(p=0.487 ; p=0.963)$.

Microglia. TBI did not increase microglia levels in the OFC, PrL, or $\operatorname{HPC}(F(1,24)=$ $2.041, p=0.166 ; F(1,24)=0.159, p=0.743 ; F(1,23)=0.550, p=0.466 ;$ Figure 8$)$. Minocycline did not impact the number of microglia in either the $\mathrm{OFC}$ or $\operatorname{PrL}(F(1,24)=0.846, p=0.367$; $F(1,24)=2.395, p=0.135)$. In the HPC, minocycline decreased microglia numbers compared to sham rats $(F(1,23)=9.89, p=0.004$; Figure $8 C)$. Minocycline did not differentially affect microglia in TBI rats in the OFC, PrL, or $\operatorname{HPC}(F(1,24)=2.771, p=0.991 ; F(1,24)=0.465, p=$ $0.339 ; F(1,23)=1.117, p=0.301 ;$ Figure 8$)$. 

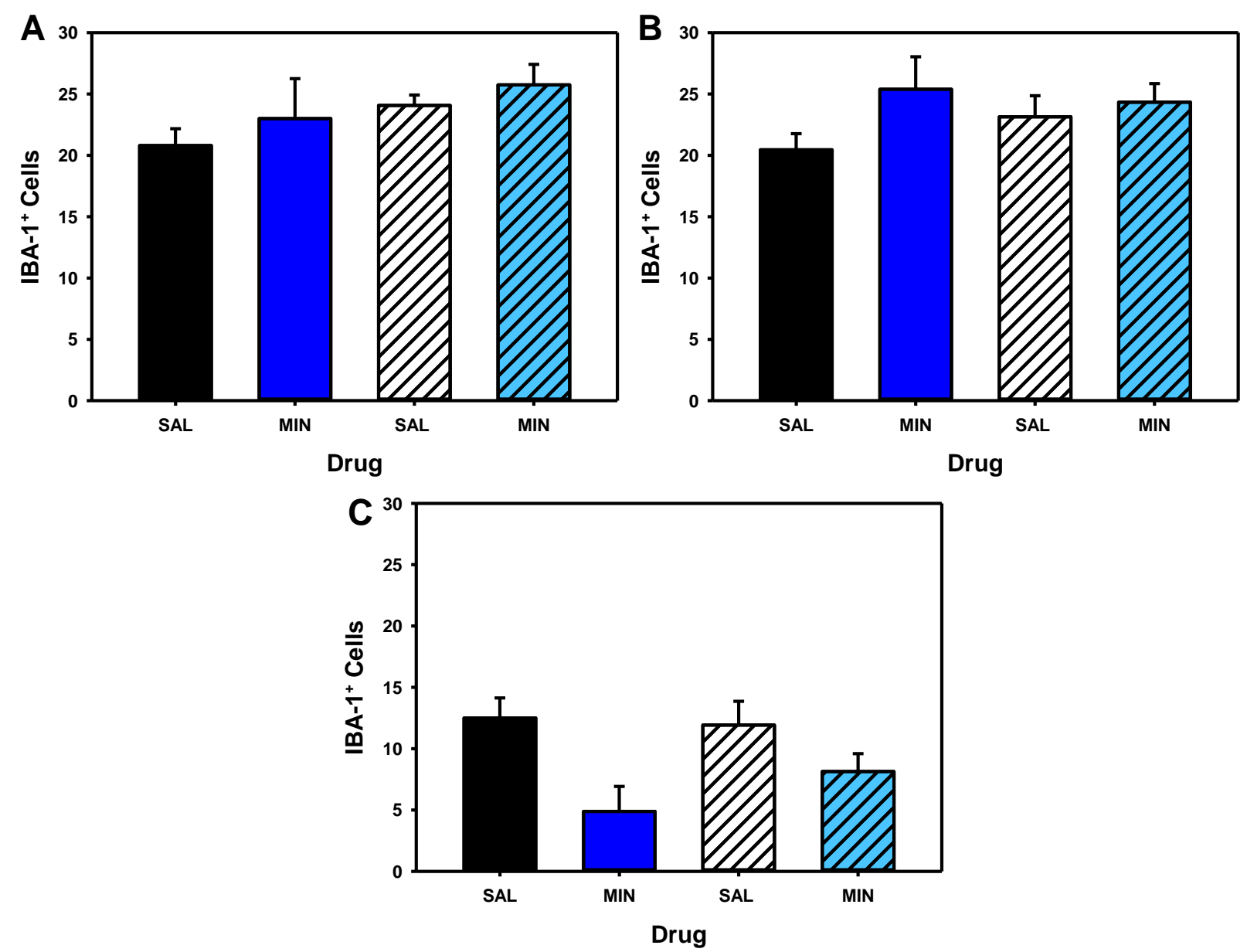

Figure 8. Number of microglia in the A) OFC B) PrL C) HPC. TBI did not increase microglia in the OFC, PrL, or HPC $(p=0.166 ; p=0.743 ; p=0.466)$. Number of microglia in the HPC was decreased in minocycline rats compared to saline rats $(p=0.004)$.

\section{Discussion}

This study examined the effectiveness of minocycline as a treatment for TBI-induced impulsivity and inattention at early (1-hour post-injury) and late ( 8 weeks post-injury) time points. We hypothesized that minocycline would reduce cognitive impairments for both treatment groups, decrease lesion size in the rats treated at the early time point, and decrease the number of microglia in rats treated in the early and late time points. Brain injury substantially 
increased impulsivity and inattention, which resulted in a decrease in overall performance on the task (task efficacy index). The CCI model was effective in causing tissue loss in TBI rats compared to shams. Our histological findings indicated that microglia were not increased at 12 weeks post-injury in the OFC, PrL, or HPC. Beyond a few subtle effects, minocycline failed to treat any TBI-related deficits such as impulsivity and inattention. Minocycline caused minor changes in behavior that progressed slowly (e.g., reduced premature responding over time; increased accuracy over time; increased task performance over time), but these subtle changes were not specific to TBI-related deficits. Additionally, minocycline did not decrease the size of the lesion or number of microglia in TBI rats.

\section{TBI-Related Changes}

Our TBI-related behavioral changes on the 5CSRT were consistent with previous studies. The increased impulsivity was in line with other studies done by our lab using the 5CSRT, as well as studies that have used alternative impulsive behavioral measures (Hehar et al., 2015; Martens et al., 2019; Mychasiuk et al., 2015; Vonder Haar et al., 2016). The changes in attention following TBI were consistent with previous work on the 5CSRT (Martens et al., 2019; Vonder Haar et al., 2016). Additionally, the pattern of omissions and task efficacy index was similar to work from previous 5CSRT studies (Martens et al., 2019; Vonder Haar et al., 2016). Together, these results indicate that we replicated previous studies in which severe TBI induces impulsive behavior and attentional impairments. In addition to behavioral changes, damage from the bilateral frontal CCI was consistent with what has been produced in prior work (Martens et al., 2019; Scott \& Vonder Haar, 2019; Shaver et al., 2019).

Microglia increases after TBI are inconsistent within the literature. In this study, there were no increases in microglia in the OFC, PrL, or HPC 12 weeks after a severe TBI. Several 
factors could have contributed to the differences in microglia expression after TBI, including injury site, the severity of the injury, or the time of tissue extraction post-injury. Previous work in rodent severe TBI models demonstrated increased microglia after TBI (Lam et al., 2013; Simon et al., 2018) These differences could be a result of varying times post-injury the tissue was taken. In our study, the tissue was harvested at 12 weeks post-injury. In the studies mentioned above, tissue was taken nine weeks post-injury, seven days post-injury, and 12 days post-injury (Lam et al., 2013; Simon et al., 2018). Yet, in other severe models of TBI, microglia levels were increased up to 12 weeks after the initial injury (Henry et al., 2020). The inconsistencies between this study and previous work may be due to food restriction. Rats in our study were maintained at $85 \%$ food restriction to ensure they were motivated to complete the 5CSRT daily. Interestingly, food restriction alone decreases the number of microglia in rodents (Yegla \& Foster, 2019). A 50\% controlled diet suppressed levels of microglia after TBI compared to rats fed ad libitum (Loncareic-Vasiljkovic et al., 2012). Although this diet was more restricted than what our rats received, caloric restriction may contribute to the differences in our microglia data, as compared to previous work.

While microglia counts may reflect some degree of pathology, microglia activation after TBI is one way to measure neuroinflammation. This prolonged neuroinflammatory response is multifaceted and other factors, such as cytokines, can also be affected. As microglia activity changes in the post-injury state, their characteristics and the cytokines they produce/respond to also change. Therefore, some characterize microglia into two states, M1-like or M2-like, to predict/infer cytokine activity based on microglia levels. While many people simplify microglia to simply M1-like or M2-like phenotypes, they can present a spectrum of pro- and antiinflammatory actions. Pro-inflammatory microglia are reactive with ameboid-like cell bodies, 
thick processes, and release predominantly pro-inflammatory cytokines (IL-1 $\beta$, IL-6, TNF- $\alpha$ ) chemokines, and reactive oxygen species (Kumar et al., 2016). Anti-inflammatory microglia are surveillant type that are ramified with smaller cell bodies and long, complex processes, and release anti-inflammatory factors such as TGF- $\beta$ (Kumar et al., 2016). In stroke, M2-like microglia also release TGF- $\beta$ (Hu et al., 2012). For this study, we measured microglia via cell count which makes it difficult to infer the type of cytokines that would have been increased or decreased. Future work could add an additional measure to test for cytokine levels. In previous work with a severe bilateral frontal injury, IL-12 was increased in the frontal cortex at 14 weeks post-injury, but other cytokines such as IL-6, IL-10, IL-1 $\beta$, and IFN- $\gamma$ were comparable to sham rats (Vonder Haar et al., 2016). Similarly, at 10 weeks post-injury, IL-12 was the only cytokine significantly increased compared to shams (Vonder Haar et al., 2017). With the same injury model and severity, it appears that there is no robust increase in cytokine levels at these later time points.

Relative to microglia, astrocytes contribute less to the pro-inflammatory response to TBI. After TBI, microglia become activated and release ATP and inflammatory cytokines that drive astrocytes to a reactive state (Jha, Jo, Kim, \& Suk, 2019; Liddelow et al., 2017). Interestingly, without microglia, astrocytes alone do not have a significant pro-inflammatory response. Exposure to lipopolysaccharide (LPS) in vitro does not prompt astrogliosis without the presence of activated microglia, but when microglia are primed with LPS, the astrocytes become reactive (Liddelow et al., 2017). Likewise, after TBI and depletion of microglia, the number of reactive astrocytes and pro-inflammatory markers were reduced (Witcher et al., 2018). These studies suggest that the neuroinflammatory response after TBI is more reliant on microglia than astrocytes. Regardless, astrocytes modulate microglial states by releasing factors such as 
chemokines and cytokines, including IFN- $\gamma$ (promotes pro-inflammatory microglia response) and TGF- $\beta$ (attenuates microglial activation) (Jha et al., 2019). Thus, astrogliosis can drive both pro and anti-inflammatory effects after TBI, but it is likely that the sharp surge in neuroinflammation is modulated by microglia. For these reasons, microglia were the primary focus of this study, but future work could consider the role of astrocytes in the neuroinflammatory response to TBI.

\section{Minocycline}

This was the first study using minocycline to treat TBI-induced impulsivity and inattention beginning at 8 weeks post-injury. However, treatments starting at 1-hour and 8 weeks post-injury failed to treat impulsivity and inattention. Our study fails to replicate some prior literature in which minocycline reduced cognitive deficits (Lam et al., 2013; Kovesdi et al., 2012; Kumar et al., 2014; Sangobowale et al., 2018; Simon et al., 2018). Even studies that matched parameters (injury severity, age of rats, and dose) to the current study successfully reduced impairments, whereas the current study failed to see such differences. A possible explanation of this is the complexity of the behavioral tasks being used. Due to the challenging nature of the task, one might consider completing this task daily to be enriching for the rats. In fact, environmental enrichment can decrease cognitive deficits after TBI (de la Tremblaye, Cheng, Bondi, \& Kline, 2019). Despite the possible enrichment effect gained from the 5CSRT, it is unlikely that enrichment can explain the failures of minocycline because of the design of this study. By having an early and late treatment group, the early treatment condition would have controlled for the potential enriching aspect of the 5CSRT because the treatment took place before post-injury testing. Thus, we are confident that the 5CSRT did not hinder any potential therapeutic effects of minocycline, and the null findings are indicative of minocycline being unable to treat psychiatric-like symptoms after TBI. 
Furthermore, minocycline reduced hippocampal-based cognitive deficits in previous research, but it was insufficient to decrease impulsivity and inattention. With complex behaviors such as the 5CSRT, it is possible that it is harder to recover from the damage since these behaviors are dependent on more areas of the brain. However, in previous work, we have been able to overcome these chronic deficits, although only transiently. Treatment with cathodal transcranial direct current stimulation reduced impulsivity measured by the 5CSRT after TBI (Martens et al., 2019). Minocycline alone does not appear to be an effective treatment for such cognitive deficits, but it is clear that these impairments can be treated. Transcranial direct current stimulation (tDCS) and minocycline have different mechanisms of action. The presumed mechanism of cathodal tDCS treatment are to increase dopamine levels, whereas minocycline is proposed to decrease neuroinflammation by reducing pro-inflammatory microglial state (Tanaka et al., 2013; Kobayashi et al., 2013). It is unknown whether treating dopamine dysfunction or neuroinflammation would be more useful to treat cognitive impairments after TBI, and more work is needed to determine this. Interestingly, microglia express dopamine receptors that can alter their activity and are upregulated after injury (Huck et al., 2015; Zhang et al., 2015). Specifically, dopamine receptor 2 on microglia can modulate innate immunity in microglia and agonism of these receptors decreases the post-stroke pro-inflammatory response (Zhang et al., 2015). Both dopamine and neuroinflammation are dysregulated after TBI and they might be interacting with one another to drive cognitive deficits. Future research should explore this relationship to help with the development of multifaceted treatments.

In the current study minocycline did not affect microglia levels or lesion size, contrary to previous studies (Adembri et al., 2014; Haber et al., 2018; Hanlon et al., 2017; Lam et al., 2013; Simon et al., 2018; Vonder Haar et al., 2016). Our tissue samples were not collected until 12 
weeks after the injury and could be the reason that we did not see similar microglia numbers as in previous work with minocycline treatments. At later time points post-injury, differences in microglia levels between TBI and sham animals are inconsistent (Arulsmay, Teng, Colton, Corrigan, \& Collins-Praino, 2018; Henry et al., 2020). It is possible that we were less likely to detect a difference between minocycline and vehicle rats because by the time we collected the tissue, the microglia effect was no longer present. Additionally, as described above, the microglia levels may have been affected by the restricted diet these rats were kept on, which also may have added to the lack of differences. Treatment at the early time point did not reduce the lesion size compared to saline rats, which is inconsistent with work from the past (Adembri et al., 2014; Vonder Haar et al., 2014). However, parallel null findings in lesion size differences were reported at similar doses (Kelso et al., 2011; Kovesdi et al., 2012). In this study, to increase sensitivity to potentially subtle lesion effects, we measured both the volume of the brains and the size of the lesion. Therefore, it is likely that the null effect was a result of the ineffectiveness of minocycline to reduce lesion size after a severe bilateral frontal CCI.

Another consideration behind the ineffectiveness of minocycline could be a result of gut microbiome dysbiosis after TBI. The gut-brain-microbiota axis is a bidirectional communication system between the gut and the brain (Wang \& Wang, 2016). In this system, brain dysregulation can affect the gut, and changes in the gut can also affect the brain. The gut can modulate brain activity through communication via the immune system, short-chain fatty acids, and efferent vagus signals. These efferent signals can affect brain neurotransmitter levels, inflammatory factors in the brain, and feedback on the HPA axis (Carabotti, Scirocco, Maselli, \& Severi, 2015; Kim \& Shin, 2018). Brain injury can create dysbiosis in the gut within 6 hours of the initial injury and persist for up to 30 days (Matharu et al., 2019). There are no studies directly linking 
gut dysbiosis after TBI to cognitive deficits, but antibiotic use can create gut dysbiosis and increase cognitive impairments (Fröhlich et al., 2016). Our study used a high dose of antibiotics for 5 days, which may have induced further gut dysbiosis and exacerbated our cognitive dysfunctions. In fact, in the studies that successfully treat cognitive impairments after TBI, they administered minocycline once daily versus our twice daily (Kovesdi et al., 2012; Kumar et al., 2014; Lam et al., 2013; Sangobowale et al., 2018; Simon et al., 2018). It is important to note that the gut dysbiosis-driven cognitive impairments were induced with a tetracycline cocktail of antibiotics, which may be more effective in depleting all bacteria compared to minocycline. Thus, it is inconclusive how minocycline effects post-injury gut dysbiosis-driven cognitive deficits. However, future work should consider the gut-brain axis when using minocycline or other antibiotics to treat post-injury dysfunction.

\section{Neuroinflammation and Cognitive Deficits}

Traumatic brain injury did not increase microglia levels at 12 weeks after the injury in our study, and in attempting to reduce neuroinflammation, it was ineffective in treating cognitive deficits. In the absence of brain injury, neuroinflammation alone can increase cognitive deficits. Chronic administration of lipopolysaccharide (LPS) to the lateral ventricles resulted in increased hippocampus-based cognitive impairments (Belarbi et al., 2012). However, it is still unclear whether neuroinflammation could be driving complex impairments such as impulsivity, and based on the results of the current study, it appears it may not be enough. Despite the lack of difference in microglia levels at 12 weeks after the injury, impulsivity and inattention were still present, indicating that alternative pathways may drive these deficits.

Furthermore, aside from neuroinflammation being a driving factor for cognitive impairments after TBI, dopamine dysregulation is also a common hypothesis of the field. 
Fascinatingly, there is evidence connecting neuroinflammation and dopamine after TBI. Limited work has looked at microglia and dopamine after TBI, and most evidence is corollary. An overall weakened DA system is associated with increased activated microglia (Huang et al., 2014). Increased microglia also occurred in tandem with more depletion of TH-positive cells (Acosta et al., 2015). Amplified pro-inflammatory cytokine, chemokine, and microglia expression was paired with decreased DA neurons and increased DA metabolites (Liu, Bachstetter, Cass, Lifshitz, \& Bing, 2017). Greater amoeboid microglia are associated with increased catechol-OMethyl transferase, which degrades catecholamines such as DA (Redell \& Dash, 2007). The proinflammatory cytokine IL-1 $\beta$, which is released by pro-inflammatory microglia, was related to a higher amount of cocaine self-stimulation, paired with decreased D1 receptor expression in the striatum, and increased D1 receptors in the accumbens (Vonder Haar et al., 2019). Finally, increased pro-inflammatory cytokines are positively related to impulsive-like behavior, which is indicative of dopamine deficiency (Vonder Haar et al., 2016). There is a relationship between microglia and dopamine after TBI, and together, they may be driving cognitive impairments. Additionally, the gut-brain axis plays an important role in both neuroinflammation and dopamine levels. Brain injury can lead to gut dysbiosis which can exacerbate TBI-related deficits. Chronic administration of an antibiotic cocktail decreased dopamine levels in the brain stem (O'Connor et al., 2019). Taken together with the results of this study, administration of minocycline could have worsened gut dysbiosis after TBI, and in turn, changed dopamine levels within the brain. The persistent impulsivity and inattention the rats in this study exhibited could have been an artifact of the neuroinflammation/dopaminergic interaction. Future research will consider studying this relationship further.

\section{Limitations and Future Directions}


A limitation of this work was the relatively unknown mechanisms of minocycline. Although previous work has linked the anti-inflammatory effects of minocycline by the inhibition of TLR4 upregulation on microglia, the mechanisms are not precise (Zhang et al., 2015). Minocycline being ineffective to treat psychiatric-like symptoms could be due to mechanisms of the drug not being an adequate manipulation of microglia to reduce neuroinflammation. A future direction would be to use a small-molecule colony-stimulating factor 1 receptor (CSF1R) inhibitor, PLX5622, that can selectively and rapidly deplete microglia (Erblich, Zhu, Etgen, Dobrenis, \& Pollard, 2011). Treatments with PLX5622 after TBI can deplete upwards of $90 \%$ of microglia, and after the repopulation of microglia, there is a reduction in pro-inflammatory markers (Henry et al., 2020). This new method of depleting and repopulating microglia may be more effective in treating cognitive impairments after TBI, and future work should consider using such methods.

Another limitation of this study was the quantification of microglia. By using IBA-1, we were only able to measure microglia via cell count instead of looking for phenotypic changes (Ito et al., 1998). Future work should consider an alternative approach, such as CD68, a marker of active macrophages or pro-inflammatory microglia (Hopperton, Mohammad, Trepanier, Giuliano, \& Bazinet, 2018). Using IBA-1 co-stained with CD68 would allow for the quantification and the ability to differentiate between pro-inflammatory and anti-inflammatory microglia.

Only adult male rats were used in this study, which limits the translatability of this work. Although there are higher rates of TBIs amongst males, it is still important to consider both sexes in research (Dewan et al., 2018). After TBI, males and females have varying inflammatory and dopaminergic responses (Doran et al., 2019; Villapol, Loane, \& Burns, 2017; Wagner et al., 
2005). Therefore, including both males and females within a study would significantly increase the sample size to be able to account for sex differences. Despite the increased sample size, future work should consider using both males and females. Age of injury can also impact the post-injury response. In human populations, increased age is associated with worse functional outcomes after TBI (Cheng, Chi, Williams, \& Thompson, 2018). This effect can also be seen in aged mice, as aged mice had exacerbated neuroinflammatory responses and increased motor and anxiety-like behaviors (Ritzel et al., 2019). Although the long-term cognitive impairments we examined in this study may not be as pertinent to the aging population, future work should address such issues.

\section{Conclusions}

This work has revealed that minocycline is an ineffective treatment to reduce impulsive and attention deficits caused by TBI. We replicated our past TBI-related deficits of increased impulsivity and inattention, which increases confidence that the present minocycline findings were due to a null effect of the drug and not methodologic errors. Given that our minocycline treatment did not decrease neuroinflammation or reduce behavioral dysfunction, other therapies should be explored. 


\section{Appendices}

Table 1: Five-choice serial reaction time task training stages

\begin{tabular}{|c|c|c|c|c|}
\hline Training stage & Limited hold (s) & $\begin{array}{l}\text { Stimulus } \\
\text { duration (s) }\end{array}$ & $\begin{array}{l}\text { Inter-trial } \\
\text { interval (s) }\end{array}$ & $\begin{array}{l}\text { Criterion to move } \\
\text { on to next stage }\end{array}$ \\
\hline 1 & 30 & 30 & 2 & $\geq 30$ correct trials \\
\hline 2 & 20 & 20 & 2 & $\geq 30$ correct trials \\
\hline 3 & 10 & 10 & 5 & $\geq 50$ correct trials \\
\hline 4 & 5 & 5 & 5 & $\begin{array}{l}\geq 50 \text { correct trials } \\
>80 \% \text { accuracy }\end{array}$ \\
\hline 5 & 5 & 2.25 & 5 & $\begin{array}{l}\geq 50 \text { correct trials } \\
>80 \% \text { accuracy } \\
<20 \% \text { omissions }\end{array}$ \\
\hline 6 & 5 & 1.25 & 5 & $\begin{array}{l}\geq 50 \text { correct trials } \\
>80 \% \text { accuracy } \\
<20 \% \text { omissions }\end{array}$ \\
\hline 7 & 5 & 1 & 5 & $\begin{array}{l}\geq 50 \text { correct trials } \\
>80 \% \text { accuracy } \\
<20 \% \text { omissions }\end{array}$ \\
\hline 8 & 5 & 0.9 & 5 & $\begin{array}{l}\geq 50 \text { correct trials } \\
>80 \% \text { accuracy } \\
<20 \% \text { omissions }\end{array}$ \\
\hline 9 & 5 & 0.8 & 5 & $\begin{array}{l}\geq 50 \text { correct trials } \\
>80 \% \text { accuracy } \\
<20 \% \text { omissions }\end{array}$ \\
\hline 10 & 5 & 0.7 & 5 & $\begin{array}{l}\geq 50 \text { correct trials } \\
>80 \% \text { accuracy } \\
<20 \% \text { omissions }\end{array}$ \\
\hline 11 & 5 & 0.6 & 5 & $\begin{array}{l}\geq 50 \text { correct trials } \\
>80 \% \text { accuracy } \\
<20 \% \text { omissions }\end{array}$ \\
\hline 12 & 5 & 0.5 & 5 & $\begin{array}{l}\geq 50 \text { correct trials } \\
>80 \% \text { accuracy } \\
<20 \% \text { omissions }\end{array}$ \\
\hline
\end{tabular}


Table 2: Premature

Early

\begin{tabular}{lccccccccc}
\hline Variable & $\beta$ & $t$ & $p$ & $\beta$ & $t$ & $p$ & $\beta$ & $t$ & $p$ \\
\hline TBI & 1.14 & 3.55 & $0.001^{* *}$ & 0.04 & 0.29 & 0.775 & 1.03 & 5.45 & $<0.001^{* * *}$ \\
MINO & -0.30 & -0.83 & 0.419 & -0.23 & -1.37 & 0.181 & & & \\
Week & 0.00 & -0.09 & 0.927 & 0.13 & 3.48 & $0.001^{* *}$ & -0.03 & -1.16 & 0.245 \\
Base & 0.13 & 1.15 & 0.264 & 0.79 & 13.68 & $<0.001^{* * *}$ & 0.36 & $4.03<0.001^{* * *}$ \\
TBI x MINO & 0.05 & 0.09 & 0.926 & 0.26 & 1.25 & 0.220 & & & \\
TBI x Week & 0.00 & -0.03 & 0.978 & -0.1 & -2.22 & $0.027^{*}$ & 0.04 & 1.19 & 0.235 \\
MINO x Week & -0.15 & -3.48 & $<0.001^{* * *}$ & -0.08 & -1.49 & 0.136 & & & \\
TBI x MINO x Week & 0.07 & 1.25 & 0.211 & 0.07 & 0.96 & 0.339 & & & \\
\hline
\end{tabular}

Table 3: Accuracy

Early

\begin{tabular}{lccccccccc}
\hline Variable & $\beta$ & $t$ & $p$ & $\beta$ & $t$ & $p$ & $\beta$ & $t$ & $p$ \\
\hline TBI & -1.25 & -3.64 & $0.001^{* *}$ & -0.07 & -0.69 & 0.496 & -1.14 & $-5.46<0.001^{* * *}$ \\
MINO & 0.26 & 0.68 & 0.507 & -0.05 & -0.49 & 0.628 & & & \\
Week & 0.05 & 2.86 & $0.004^{* *}$ & 0.05 & 2.3 & $0.022^{*}$ & 0.07 & 3.4 & $0.001^{* *}$ \\
Base & 0.33 & 2.55 & 0.018 & 0.94 & 24.2 & $<0.001^{* * *}$ & 0.42 & $4.22<0.001^{* * *}$ \\
TBI x MINO & -0.09 & -0.19 & 0.854 & 0.13 & 0.95 & 0.351 & & & \\
TBI x Week & -0.06 & -2.24 & $0.025^{*}$ & -0.05 & -1.96 & $0.050^{*}$ & -0.04 & -1.5 & 0.133 \\
MINO x Week & 0.06 & 2.27 & $0.023^{*}$ & 0.05 & 1.48 & 0.138 & & & \\
TBI x MINO x Week & 0.06 & 1.56 & 0.119 & -0.04 & -1.02 & 0.308 & & & \\
\hline
\end{tabular}

Table 4: Omissions

\begin{tabular}{lccccccccc} 
Early & \multicolumn{1}{c}{ Late } & \multicolumn{1}{c}{ Late Injury Effect } \\
\hline Variable & $\beta$ & $t$ & $p$ & $\beta$ & $t$ & $p$ & $\beta$ & $t$ & $p$ \\
\hline TBI & 1.04 & 4.15 & $<0.001^{* * *}$ & 0.34 & 2.09 & $0.045^{*}$ & 0.80 & $4.62<0.001^{* * *}$ \\
MINO & 0.01 & 0.03 & 0.973 & 0.39 & 1.91 & 0.066 & & \\
Week & -0.31 & -10.32 & $<0.001^{* * *}$ & -0.27 & -6.29 & $<0.001^{* * *}$ & -0.30 & $-9.96<0.001^{* * *}$ \\
Base & 0.38 & 4.11 & $<0.001^{* * *}$ & 0.73 & 11.22 & $<0.001^{* * *}$ & 0.44 & $5.4<0.001^{* * *}$ \\
TBI x MINO & -0.22 & -0.59 & 0.558 & -0.47 & -1.84 & 0.075 & & & \\
TBI x Week & 0.18 & 4.13 & $<0.001^{* * *}$ & 0.33 & 6.4 & $<0.001^{* * *}$ & 0.03 & 0.74 & 0.457 \\
MINO x Week & 0.07 & 1.44 & 0.150 & 0.25 & 3.89 & $<0.001^{* * *}$ & & & \\
TBI x MINO x Week & -0.18 & -2.89 & $0.003^{* *}$ & -0.3 & -3.63 & $<0.001^{* * *}$ & & & \\
\hline
\end{tabular}


Table 5: Task Efficancy Index

Early

\begin{tabular}{lccccccccc}
\hline Variable & $\beta$ & $t$ & $p$ & $\beta$ & $t$ & $p$ & $\beta$ & $t$ & $p$ \\
\hline TBI & -1.39 & -4.10 & $0.001^{* *}$ & -0.1 & -0.93 & 0.360 & -1.23 & $-5.56<0.001^{* * *}$ \\
MINO & 0.15 & 0.40 & 0.693 & -0.07 & -0.54 & 0.594 & & & \\
Week & 0.10 & 5.70 & $<0.001^{* * *}$ & 0.09 & 3.94 & $<0.001^{* * *}$ & 0.12 & $6.96<0.001^{* * *}$ \\
Base & 0.28 & 2.24 & $0.036^{*}$ & 0.91 & 20.66 & $<0.001^{* * *}$ & 0.37 & 3.6 & $0.001^{* *}$ \\
TBI x MINO & 0.12 & 0.23 & 0.817 & 0.1 & 0.67 & 0.510 & & & \\
TBI x Week & 0.04 & 1.61 & 0.109 & -0.1 & -3.72 & $<0.001^{* * *}$ & 0.02 & 0.86 & 0.389 \\
MINO x Week & 0.06 & 2.20 & $0.028^{*}$ & -0.01 & -0.22 & 0.828 & & & \\
TBI x MINO x Week & -0.02 & -0.61 & 0.540 & 0.03 & 0.74 & 0.461 & & & \\
\hline
\end{tabular}

Table 6: Trials

Early Late Late Injury Effect

\begin{tabular}{lccccccccc}
\hline Variable & $\beta$ & $t$ & $p$ & $\beta$ & $t$ & $p$ & $\beta$ & $t$ & $p$ \\
\hline TBI & -1.32 & -3.81 & $0.001^{* *}$ & -0.13 & -0.91 & 0.373 & -1.09 & $-4.24<0.001^{* * *}$ \\
MINO & -0.18 & -0.46 & 0.648 & -0.09 & -0.5 & 0.621 & & & \\
Week & 0.10 & 4.97 & $<0.001^{* * *}$ & 0.09 & 3.03 & $0.003^{* *}$ & 0.15 & $7.33<0.001^{* * *}$ \\
Base & 0.32 & 2.39 & 0.026 & 0.87 & 14.83 & $<0.001^{* * *}$ & 0.25 & 2.09 & $0.045^{*}$ \\
TBI x MINO & 0.37 & 0.72 & 0.480 & 0.13 & 0.61 & 0.548 & & & \\
TBI x Week & 0.03 & 1.09 & 0.278 & -0.04 & -1.14 & 0.255 & -0.03 & -1.32 & 0.187 \\
MINO x Week & 0.04 & 1.34 & 0.181 & -0.07 & -1.74 & 0.081 & & & \\
TBI x MINO x Week & 0.01 & 0.18 & 0.858 & 0.07 & 1.35 & 0.178 & & & \\
\hline
\end{tabular}

Table 7: Collection Latency

\begin{tabular}{lccccccccc} 
Early & \multicolumn{1}{c}{ Late } & \multicolumn{1}{c}{ Late Injury Effect } \\
\hline Variable & $\beta$ & $t$ & $p$ & $\beta$ & $t$ & $p$ & $\beta$ & $t$ & $p$ \\
\hline TBI & -1.17 & -3.58 & $0.002^{* *}$ & -0.16 & -0.73 & 0.472 & -0.99 & $-4.66<0.001^{* * *}$ \\
MINO & 0.05 & 0.15 & 0.882 & 0.08 & 0.31 & 0.761 & & & \\
Week & 0.01 & -0.14 & 0.886 & 0.05 & 1.14 & 0.253 & -0.01 & -0.31 & 0.759 \\
Base & 0.09 & 0.76 & 0.454 & 0.71 & 8.05 & $<0.001^{* * *}$ & 0.15 & 1.53 & 0.137 \\
TBI x MINO & 0.08 & 0.17 & 0.870 & 0.06 & 0.19 & 0.851 & & & \\
TBI x Week & 0.00 & 0.01 & 0.990 & -0.08 & -1.72 & 0.085 & -0.03 & -0.76 & 0.448 \\
MINO x Week & 0.01 & 0.19 & 0.850 & 0.00 & 0.02 & 0.986 & & & \\
TBI x MINO x Week & 0.04 & 0.56 & 0.573 & 0.06 & 0.76 & 0.445 & & & \\
\hline
\end{tabular}




\section{References}

Acosta, S. A., Tajiri, N., de la Pena, I., Bastawrous, M., Sanberg, P. R., Kaneko, Y., \& Borlongan, C. V. (2015). Alpha-synuclein as a pathological link between chronic traumatic brain injury and Parkinson's disease. Journal of Cellular Physiology, 230(5), 1024-1032.

Adembri, C., Selmi, V., Vitali, L., Tani, A., Margheri, M., Loriga, B., ... \& De Gaudio, A. R. (2014). Minocycline but not tigecycline is neuroprotective and reduces the neuroinflammatory response induced by the superimposition of sepsis upon traumatic brain injury. Critical Care Medicine, 42(8), e570-e582.

Ahmed, S., Venigalla, H., Mekala, H. M., Dar, S., Hassan, M., \& Ayub, S. (2017). Traumatic brain injury and neuropsychiatric complications. Indian Journal of Psychological Medicine, 39(2), 114.

Alderman, N. (2003). Contemporary approaches to the management of irritability and aggression following traumatic brain injury. Neuropsychological Rehabilitation, 13(1-2), 211-240.

Aron, A. R., Fletcher, P. C., Bullmore, E. T., Sahakian, B. J., \& Robbins, T. W. (2003). Stopsignal inhibition disrupted by damage to right inferior frontal gyrus in humans. Nature Neuroscience, 6(2), 115.

Arulsamy, A., Teng, J., Colton, H., Corrigan, F., \& Collins-Praino, L. (2018). Evaluation of early chronic functional outcomes and their relationship to pre-frontal cortex and hippocampal pathology following moderate-severe traumatic brain injury. Behavioural Brain Research, 348, 127-138.

Belarbi, K., Jopson, T., Tweedie, D., Arellano, C., Luo, W., Greig, N. H., \& Rosi, S. (2012). TNF- $\alpha$ protein synthesis inhibitor restores neuronal function and reverses cognitive deficits induced by chronic neuroinflammation. Journal of Neuroinflammation, 9(1), 23.

Belmont, A., Agar, N., \& Azouvi, P. (2009). Subjective fatigue, mental effort, and attention deficits after severe traumatic brain injury. Neurorehabilitation and Neural Repair, 23(9), 939-944. 
Carabotti, M., Scirocco, A., Maselli, M. A., \& Severi, C. (2015). The gut-brain axis: interactions between enteric microbiota, central and enteric nervous systems. Annals of gastroenterology: quarterly publication of the Hellenic Society of Gastroenterology, 28(2), 203.

Carli, M., Robbins, T. W., Evenden, J. L., \& Everitt, B. J. (1983). Effects of lesions to ascending noradrenergic neurones on performance of a 5-choice serial reaction task in rats; implications for theories of dorsal noradrenergic bundle function based on selective attention and arousal. Behavioural Brain Research, 9(3), 361-380.

Chen, C. J., Wu, C. H., Liao, Y. P., Hsu, H. L., Tseng, Y. C., Liu, H. L., \& Chiu, W. T. (2012). Working memory in patients with mild traumatic brain injury: functional MR imaging analysis. Radiology, 264(3), 844-851.

Cheng, C., Chi, N. C., Williams, E., \& Thompson, H. J. (2018). Examining age-related differences in functional domain impairment following traumatic brain injury. International Journal of Older People Nursing, 13(4), e12208.

Cheng, J. P., Shaw, K. E., Monaco, C. M., Hoffman, A. N., Sozda, C. N., Olsen, A. S., \& Kline, A. E. (2012). A relatively brief exposure to environmental enrichment after experimental traumatic brain injury confers long-term cognitive benefits. Journal of Neurotrauma, 29(17), 2684-2688.

de la Tremblaye, P. B., Cheng, J. P., Bondi, C. O., \& Kline, A. E. (2019). Environmental enrichment, alone or in combination with various pharmacotherapies, confers marked benefits after traumatic brain injury. Neuropharmacology, 145(Pt A), 13-24.

Dewan, M. C., Rattani, A., Gupta, S., Baticulon, R. E., Hung, Y. C., Punchak, M., ... \& Rosenfeld, J. V. (2018). Estimating the global incidence of traumatic brain injury. Journal of Neurosurgery, 1(aop), 1-18.

Dixon, C., Clifton, G. L., Lighthall, J. W., Yaghmai, A. A., \& Hayes, R. L. (1991). A controlled cortical impact model of traumatic brain injury in the rat. Journal of Neuroscience Methods, 39(3), 253-262. doi:10.1016/0165-0270(91)90104-8 
Dixon, C. E., Kochanek, P. M., Yan, H. Q., Schiding, J. K., Griffith, R. G., Baum, E., ... \& DeKosky, S. T. (1999). One-year study of spatial memory performance, brain morphology, and cholinergic markers after moderate controlled cortical impact in rats. Journal of Neurotrauma, 16(2), 109-122.

Dockree, P. M., Kelly, S. P., Roche, R. A., Hogan, M. J., Reilly, R. B., \& Robertson, I. H. (2004). Behavioural and physiological impairments of sustained attention after traumatic brain injury. Cognitive Brain Research, 20(3), 403-414.

Donat, C. K., Scott, G., Gentleman, S. M., \& Sastre, M. (2017). Microglial activation in traumatic brain injury. Frontiers in Aging Neuroscience, 9, 208.

Doran, S. J., Ritzel, R. M., Glaser, E. P., Henry, R. J., Faden, A. I., \& Loane, D. J. (2019). Sex differences in acute neuroinflammation after experimental traumatic brain injury are mediated by infiltrating myeloid cells. Journal of Neurotrauma, 36(7), 1040-1053.

Duncan, C. C., Kosmidis, M. H., \& Mirsky, A. F. (2005). Closed head injury-related information processing deficits: an event-related potential analysis. International Journal of Psychophysiology, 58(2-3), 133-157.

Dyer, K. F., Bell, R., McCann, J., \& Rauch, R. (2006). Aggression after traumatic brain injury: Analysing socially desirable responses and the nature of aggressive traits. Brain Injury, 20(11), 1163-1173.

Erblich, B., Zhu, L., Etgen, A. M., Dobrenis, K., \& Pollard, J. W. (2011). Absence of colony stimulation factor-1 receptor results in loss of microglia, disrupted brain development and olfactory deficits. PloS One, 6(10).

Ferster, C. B., \& Skinner, B. F. (1957). Schedules of reinforcement.

Fröhlich, E. E., Farzi, A., Mayerhofer, R., Reichmann, F., Jačan, A., Wagner, B., ... \& Kashofer, K. (2016). Cognitive impairment by antibiotic-induced gut dysbiosis: analysis of gut microbiota-brain communication. Brain, Behavior, and Immunity, 56, 140-155.

Garrido-Mesa, N., Zarzuelo, A., \& Gálvez, J. (2013). Minocycline: far beyond an antibiotic. British Journal of Pharmacology, 169(2), 337-352. 
Haber, M., James, J., Kim, J., Sangobowale, M., Irizarry, R., Ho, J., ... \& Bergold, P. J. (2018). Minocycline plus N-acteylcysteine induces remyelination, synergistically protects oligodendrocytes and modifies neuroinflammation in a rat model of mild traumatic brain injury. Journal of Cerebral Blood Flow \& Metabolism, 38(8), 1312-1326.

Hamm, R. J., Pike, B. R., Temple, M. D., O'Dell, D. M., \& Lyeth, B. G. (1995). The effect of postinjury kindled seizures on cognitive performance of traumatically brain-injured rats. Experimental Neurology, 136(2), 143-148.

Hanlon, L. A., Huh, J. W., \& Raghupathi, R. (2016). Minocycline transiently reduces microglia/macrophage activation but exacerbates cognitive deficits following repetitive traumatic brain injury in the neonatal rat. Journal of Neuropathology \& Experimental Neurology, 75(3), 214-226.

Hanlon, L. A., Raghupathi, R., \& Huh, J. W. (2017). Differential effects of minocycline on microglial activation and neurodegeneration following closed head injury in the neonate rat. Experimental neurology, 290, 1-14.

Henry, C. J., Huang, Y., Wynne, A., Hanke, M., Himler, J., Bailey, M. T., ... \& Godbout, J. P. (2008). Minocycline attenuates lipopolysaccharide (LPS)-induced neuroinflammation, sickness behavior, and anhedonia. Journal of Neuroinflammation, 5(1), 15.

Henry, R. J., Ritzel, R. M., Barrett, J. P., Doran, S. J., Jiao, Y., Leach, J. B., ... \& Loane, D. J. (2020). Microglial depletion with CSF1R inhibitor during chronic phase of experimental traumatic brain injury reduces neurodegeneration and neurological deficits. Journal of Neuroscience, 40(14), 2960-2974.

Hehar, H., Yeates, K., Kolb, B., Esser, M. J., \& Mychasiuk, R. (2015). Impulsivity and concussion in juvenile rats: examining molecular and structural aspects of the frontostriatal pathway. PLoS One, 10(10), e0139842.

Hoffman, S. W., Fülöp, Z., \& Stein, D. G. (1994). Bilateral frontal cortical contusion in rats: behavioral and anatomie consequences. Journal of Neurotrauma, 11(4), 417-431. 
Hopperton, K. E., Mohammad, D., Trépanier, M. O., Giuliano, V., \& Bazinet, R. P. (2018). Markers of microglia in post-mortem brain samples from patients with Alzheimer's disease: a systematic review. Molecular Psychiatry, 23(2), 177-198.

Hu, X., Li, P., Guo, Y., Wang, H., Leak, R. K., Chen, S., ... \& Chen, J. (2012). Microglia/macrophage polarization dynamics reveal novel mechanism of injury expansion after focal cerebral ischemia. Stroke, 43(11), 3063-3070.

Huang, E. Y. K., Tsai, T. H., Kuo, T. T., Tsai, J. J., Tsui, P. F., Chou, Y. C., ... \& Chen, Y. H. (2014). Remote effects on the striatal dopamine system after fluid percussion injury. Behavioural Brain Research, 267, 156-172.

Huck, J. H., Freyer, D., Böttcher, C., Mladinov, M., Muselmann-Genschow, C., Thielke, M., ... \& Priller, J. (2015). De novo expression of dopamine D2 receptors on microglia after stroke. Journal of Cerebral Blood Flow \& Metabolism, 35(11), 1804-1811.

Ito, D., Imai, Y., Ohsawa, K., Nakajima, K., Fukuuchi, Y., \&amp; Kohsaka, S. (1998). Microglia-specific localisation of a novel calcium binding protein, Iba1. Molecular Brain Research, 57(1), 1-9. doi:10.1016/s0169-328x(98)00040-0

Jin, X., Ishii, H., Bai, Z., Itokazu, T., \& Yamashita, T. (2012). Temporal changes in cell marker expression and cellular infiltration in a controlled cortical impact model in adult male C57BL/6 mice. PloS One, 7(7), e41892.

Jha, M. K., Jo, M., Kim, J. H., \& Suk, K. (2019). Microglia-Astrocyte Crosstalk: An Intimate Molecular Conversation. The Neuroscientist : a review journal bringing neurobiology, neurology and psychiatry, 25(3), 227-240.

Kelso, M. L., Scheff, N. N., Scheff, S. W., \& Pauly, J. R. (2011). Melatonin and minocycline for combinatorial therapy to improve functional and histopathological deficits following traumatic brain injury. Neuroscience Letters, 488(1), 60-64.

Kim, Y. K., \& Shin, C. (2018). The microbiota-gut-brain axis in neuropsychiatric disorders: pathophysiological mechanisms and novel treatments. Current Neuropharmacology, 16(5), 559-573. 
Kobayashi, K., Imagama, S., Ohgomori, T., Hirano, K., Uchimura, K., Sakamoto, K., ... \& Kadomatsu, K. (2013). Minocycline selectively inhibits M1 polarization of microglia. Cell Death \& Disease, 4(3), e525-e525.

Kovesdi, E., Kamnaksh, A., Wingo, D., Ahmed, F., Grunberg, N. E., Long, J. B., ... \& Agoston, D. V. (2012). Acute minocycline treatment mitigates the symptoms of mild blast-induced traumatic brain injury. Frontiers in Neurology, 3, 111.

Kumar, A., Alvarez-Croda, D. M., Stoica, B. A., Faden, A. I., \& Loane, D. J. (2016). Microglial/macrophage polarization dynamics following traumatic brain injury. Journal of Neurotrauma, 33(19), 1732-1750.

Kumar, A., Barrett, J. P., Alvarez-Croda, D. M., Stoica, B. A., Faden, A. I., \& Loane, D. J. (2016). NOX2 drives M1-like microglial/macrophage activation and neurodegeneration following experimental traumatic brain injury. Brain, Behavior, and Immunity, 58, 291309.

Kumar, A., Rinwa, P., \& Dhar, H. (2014). Microglial inhibitory effect of ginseng ameliorates cognitive deficits and neuroinflammation following traumatic head injury in rats. Inflammopharmacology, 22(3), 155-167.

Lam, T. I., Bingham, D., Chang, T. J., Lee, C. C., Shi, J., Wang, D., ... \& Liu, J. (2013). Beneficial Effects of Minocycline and Botulinum Toxin-Induced Constraint Physical Therapy Following Experimental Traumatic Brain Injury. Neurorehabilitation and Neural Repair, 27(9), 889-899.

Lawton, T., \& Huang, M. X. (2019). Dynamic cognitive remediation for a Traumatic Brain Injury (TBI) significantly improves attention, working memory, processing speed, and reading fluency. Restorative Neurology and Neuroscience, (Preprint), 1-16.

Levin, H., Hanten, G., Max, J., Li, X., Swank, P., Ewing-Cobbs, L., ... \& Schachar, R. (2007). Symptoms of attention-deficit/hyperactivity disorder following traumatic brain injury in children. Journal of Developmental \& Behavioral Pediatrics, 28(2), 108-118. 
Liddelow, S. A., Guttenplan, K. A., Clarke, L. E., Bennett, F. C., Bohlen, C. J., Schirmer, L., ... \& Wilton, D. K. (2017). Neurotoxic reactive astrocytes are induced by activated microglia. Nature, 541(7638), 481-487.

Lighthall, J. W. (1988). Controlled cortical impact: A new experimental brain injury model. Journal of Neurotrauma, 5(1), 1-15. doi:10.1089/neu.1988.5.1

Lindner, M. D., Plone, M. A., Cain, C. K., Frydel, B., Francis, J. M., Emerich, D. F., \& Sutton, R. L. (1998). Dissociable long-term cognitive deficits after frontal versus sensorimotor cortical contusions. Journal of Neurotrauma, 15(3), 199-216.

Liu, M., Bachstetter, A. D., Cass, W. A., Lifshitz, J., \& Bing, G. (2017). Pioglitazone attenuates neuroinflammation and promotes dopaminergic neuronal survival in the nigrostriatal system of rats after diffuse brain injury. Journal of Neurotrauma, 34(2), 414-422.

Loane, D. J., \& Faden, A. I. (2010). Neuroprotection for traumatic brain injury: translational challenges and emerging therapeutic strategies. Trends in Pharmacological Sciences, 31(12), 596-604.

Loane, D. J., \& Kumar, A. (2016). Microglia in the TBI brain: the good, the bad, and the dysregulated. Experimental Neurology, 275, 316-327.

Loncarevic-Vasiljkovic, N., Pesic, V., Todorovic, S., Popic, J., Smiljanic, K., Milanovic, D., ... $\&$ Kanazir, S. (2012). Caloric restriction suppresses microglial activation and prevents neuroapoptosis following cortical injury in rats. PloS one, 7(5), e37215.

Ma, Y., Wang, J., Wang, Y., \& Yang, G. Y. (2017). The biphasic function of microglia in ischemic stroke. Progress in Neurobiology, 157, 247-272.

Martens, K. M., Pechacek, K. M., Modrak, C. G., Milleson, V. J., Zhu, B. \& Vonder Haar, C. (2019). Cathodal transcranial direct-current stimulation selectively reduces impulsivity after TBI. Journal of Neurotrauma, 36(19), 2827-2830.

Matharu, D., Dhotre, D., Balasubramanian, N., Pawar, N., Sagarkar, S., \& Sakharkar, A. (2019). Repeated mild traumatic brain injury affects microbial diversity in rat jejunum. Journal of Biosciences, 44(5), 120. 
Mathias, J. L., \& Wheaton, P. (2007). Changes in attention and information-processing speed following severe traumatic brain injury: a meta-analytic review. Neuropsychology, 21(2), 212.

McAllister, T. W. (2008). Neurobehavioral sequelae of traumatic brain injury: evaluation and management. World Psychiatry, 7(1), 3-10.

Meythaler, J., Fath, J., Fuerst, D., Zokary, H., Freese, K., Martin, H. B., ... \& Roskos, P. T. (2019). Safety and feasibility of minocycline in treatment of acute traumatic brain injury. Brain Injury, 33(5), 679-689.

Mitchell, R. H., \& Goldstein, B. I. (2014). Inflammation in children and adolescents with neuropsychiatric disorders: a systematic review. Journal of the American Academy of Child \& Adolescent Psychiatry, 53(3), 274-296.

Mychasiuk, R., Hehar, H., \& Esser, M. J. (2015). A mild traumatic brain injury (mTBI) induces secondary attention-deficit hyperactivity disorder-like symptomology in young rats. Behavioural Brain Research, 286, 285-292.

Oades, R. D., Myint, A. M., Dauvermann, M. R., Schimmelmann, B. G., \& Schwarz, M. J. (2010). Attention-deficit hyperactivity disorder (ADHD) and glial integrity: an exploration of associations of cytokines and kynurenine metabolites with symptoms and attention. Behavioral and Brain Functions, 6(1), 32.

O'connor, J. C., Lawson, M. A., Andre, C., Moreau, M., Lestage, J., Castanon, N., ... \& Dantzer, R. (2009). Lipopolysaccharide-induced depressive-like behavior is mediated by indoleamine 2, 3-dioxygenase activation in mice. Molecular Psychiatry, 14(5), 511.

O'Connor, K. M., Lucking, E. F., Golubeva, A. V., Strain, C. R., Fouhy, F., Cenit, M. C., ... \& Clarke, G. (2019). Manipulation of gut microbiota blunts the ventilatory response to hypercapnia in adult rats. EBioMedicine, 44, 618-638.

Osier, N., \& Dixon, C. E. (2016). The controlled cortical impact model of experimental brain trauma: overview, research applications, and protocol. In Injury Models of the Central Nervous System (pp. 177-192). Humana Press, New York, NY. 
Ozga, J. E., Povroznik, J. M., Engler-Chiurazzi, E. B., \& Vonder Haar, C. (2018). Executive (dys) function after traumatic brain injury: special considerations for behavioral pharmacology. Behavioural Pharmacology, 29(7), 617.

Piotrowska, A., Popiolek-Barczyk, K., Pavone, F., \& Mika, J. (2017). Comparison of the expression changes after botulinum toxin type A and minocycline administration in lipopolysaccharide-stimulated rat microglial and astroglial cultures. Frontiers in cellular and infection microbiology, 7, 141.

Ramlackhansingh, A. F., Brooks, D. J., Greenwood, R. J., Bose, S. K., Turkheimer, F. E., Kinnunen, K. M., ... \& Sharp, D. J. (2011). Inflammation after trauma: microglial activation and traumatic brain injury. Annals of Neurology, 70(3), 374-383.

Redell, J. B., \& Dash, P. K. (2007). Traumatic brain injury stimulates hippocampal catechol-Omethyl transferase expression in microglia. Neuroscience Letters, 413(1), 36-41.

Reeves, R. R., \& Panguluri, R. L. (2011). Neuropsychiatric complications of traumatic brain injury. Journal of Psychosocial Nursing and Mental Health Services, 49(3), 42-50.

Ritzel, R. M., Doran, S. J., Glaser, E. P., Meadows, V. E., Faden, A. I., Stoica, B. A., \& Loane, D. J. (2019). Old age increases microglial senescence, exacerbates secondary neuroinflammation, and worsens neurological outcomes after acute traumatic brain injury in mice. Neurobiology of Aging, 77, 194-206.

Robbins, T. (2002). The 5-choice serial reaction time task: behavioural pharmacology and functional neurochemistry. Psychopharmacology, 163(3-4), 362-380.

Robertson, K., \& Schmitter-Edgecombe, M. (2017). Focused and divided attention abilities in the acute phase of recovery from moderate to severe traumatic brain injury. Brain Injury, 31(8), 1069-1076. doi:10.1080/02699052.2017.1296192

Rochat, L., Beni, C., Annoni, J. M., Vuadens, P., \& Van der Linden, M. (2013). How inhibition relates to impulsivity after moderate to severe traumatic brain injury. Journal of the International Neuropsychological Society, 19(8), 890-898. 
Rosvold, H. E., Mirsky, A. F., Sarason, I., Bransome Jr, E. D., \& Beck, L. H. (1956). A continuous performance test of brain damage. Journal of Consulting Psychology, 20(5), 343.

Sangobowale, M. A., Grin'kina, N. M., Whitney, K., Nikulina, E., St. Laurent-Ariot, K., Ho, J. S., ... \& Bergold, P. J. (2018). Minocycline plus N-acetylcysteine reduce behavioral deficits and improve Histology with a clinically useful time window. Journal of Neurotrauma, 35(7), 907-917.

Scott, G., Zetterberg, H., Jolly, A., Cole, J. H., De Simoni, S., Jenkins, P. O., ... \& Patel, M. C. (2018). Minocycline reduces chronic microglial activation after brain trauma but increases neurodegeneration. Brain, 141(2), 459-471.

Scott, T. L., \& Vonder Haar, C. (2019). Frontal brain injury chronically impairs timing behavior in rats. Behavioural Brain Research, 356, 408-414.

Shaver, T. K., Ozga, J. E., Zhu, B., Anderson, K. G., Martens, K. M., \& Haar, C. V. (2019). Long-term deficits in risky decision-making after traumatic brain injury on a rat analog of the Iowa gambling task. Brain Research, 1704, 103-113.

Shultz, S. R., Bao, F., Omana, V., Chiu, C., Brown, A., \& Cain, D. P. (2012). Repeated mild lateral fluid percussion brain injury in the rat causes cumulative long-term behavioral impairments, neuroinflammation, and cortical loss in an animal model of repeated concussion. Journal of Neurotrauma, 29(2), 281-294.

Simon, D. W., Aneja, R. K., Alexander, H., Bell, M. J., Bayır, H., Kochanek, P. M., \& Clark, R. S. (2018). Minocycline attenuates high mobility group box 1 translocation, microglial activation, and thalamic neurodegeneration after traumatic brain injury in post-natal day 17 rats. Journal of Neurotrauma, 35(1), 130-138.

Simon, D. W., McGeachy, M. J., Bayır, H., Clark, R. S., Loane, D. J., \& Kochanek, P. M. (2017). The far-reaching scope of neuroinflammation after traumatic brain injury. Nature Reviews. Neurology, 13(3), 171-191. doi:10.1038/nrneurol.2017.13 
Simpson, G. K., Sabaz, M., \& Daher, M. (2013). Prevalence, clinical features, and correlates of inappropriate sexual behavior after traumatic brain injury: a multicenter study. The Journal of Head Trauma Rehabilitation, 28(3), 202-210.

Song, G. J., \& Suk, K. (2017). Pharmacological modulation of functional phenotypes of microglia in neurodegenerative diseases. Frontiers in Aging Neuroscience, 9, 139.

Stephens, J. A., Salorio, C. E., Gomes, J. P., Nebel, M. B., Mostofsky, S. H., \& Suskauer, S. J. (2017). Response inhibition deficits and altered motor network connectivity in the chronic phase of pediatric traumatic brain injury. Journal of Neurotrauma, 34(22), 31173123.

Stein, D. G., Brailowsky, S., \& Will, B. (1995). Brain repair. New York: Oxford University Press.

Tanaka, T., Takano, Y., Tanaka, S., Hironaka, N., Kobayashi, K., Hanakawa, T., ... \& Honda, M. (2013). Transcranial direct-current stimulation increases extracellular dopamine levels in the rat striatum. Frontiers in Systems Neuroscience, 7, 6.

Taylor, A. N., Tio, D. L., Paydar, A., \& Sutton, R. L. (2018). Sex differences in thermal, stress, and inflammatory responses to minocycline administration in rats with traumatic brain injury. Journal of Neurotrauma, 35(4), 630-638.

Tramontana, M. G., Cowan, R. L., Zald, D., Prokop, J. W., \& Guillamondegui, O. (2014). Traumatic brain injury-related attention deficits: treatment outcomes with lisdexamfetamine dimesylate (Vyvanse). Brain Injury, 28(11), 1461-1472.

Thurman, D. J., Alverson, C., Dunn, K. A., Guerrero, J., \& Sniezek, J. E. (1999). Traumatic brain injury in the United States: A public health perspective. The Journal of Head Trauma Rehabilitation, 14(6), 602-615.

Vaure, C., \& Liu, Y. (2014). A comparative review of toll-like receptor 4 expression and functionality in different animal species. Frontiers in immunology, 5, 316.

Villapol, S., Loane, D. J., \& Burns, M. P. (2017). Sexual dimorphism in the inflammatory response to traumatic brain injury. Glia, 65(9), 1423-1438. 
Vonder Haar, C., Anderson, G. D., Elmore, B. E., Moore, L. H., Wright, A. M., Kantor, E. D., ... \& Hoane, M. R. (2014). Comparison of the effect of minocycline and simvastatin on functional recovery and gene expression in a rat traumatic brain injury model. Journal of Neurotrauma, 31(10), 961-975.

Vonder Haar, C., Ferland, J. M. N., Kaur, S., Riparip, L. K., Rosi, S., \& Winstanley, C. A. (2019). Cocaine self-administration is increased after frontal traumatic brain injury and associated with neuroinflammation. European Journal of Neuroscience, 50(3), 21342145.

Vonder Haar, C., Lam, F. C. W., Adams, W. K., Riparip, L-K., Kaur, S., Muthukrishna, M., Rosi, S. \& Winstanley, C. A. (2016). Frontal traumatic brain injury in rats causes longlasting impairments in impulse control that are that are differentially sensitive to pharmacotherapeutics and associated with chronic neuroinflammation. ACS Chemical Neuroscience, 7(11), 1531-1542.

Vonder Haar, C., Martens, K. M., Riparip, L. K., Rosi, S., Wellington, C. L., \& Winstanley, C. A. (2017). Frontal Traumatic Brain Injury Increases Impulsive Decision Making in Rats: A Potential Role for the Inflammatory Cytokine Interleukin-12. Journal of Neurotrauma, 34(19), 2790-2800. doi:10.1089/neu.2016.4813

Wagner, A. K., Sokoloski, J. E., Ren, D., Chen, X., Khan, A. S., Zafonte, R. D., Michael, A. C., \& Dixon, C. E. (2005). Controlled cortical impact injury affects dopaminergic transmission in the rat striatum. Journal of Neurochemistry, 95(2), 457-465.

Wang, H. X., \& Wang, Y. P. (2016). Gut microbiota-brain axis. Chinese Medical Journal, 129(19), 2373.

Winstanley, C. A., Eagle, D. M., \& Robbins, T. W. (2006). Behavioral models of impulsivity in relation to ADHD: Translation between clinical and preclinical studies. Clinical Psychology Review, 26(4), 379-395. doi:10.1016/j.cpr.2006.01.001

Witcher, K. G., Bray, C. E., Dziabis, J. E., McKim, D. B., Benner, B. N., Rowe, R. K., ... \& Godbout, J. P. (2018). Traumatic brain injury-induced neuronal damage in the 
somatosensory cortex causes formation of rod-shaped microglia that promote astrogliosis and persistent neuroinflammation. Glia, 66(12), 2719-2736.

Wofford, K. L., Loane, D. J., \& Cullen, D. K. (2019). Acute drivers of neuroinflammation in traumatic brain injury. Neural Regeneration Research, 14(9), 1481.

Xiong, Y., Zhang, Y., Mahmood, A., Meng, Y., Zhang, Z. G., Morris, D. C., \& Chopp, M. (2012). Neuroprotective and neurorestorative effects of thymosin $\beta 4$ treatment initiated 6 hours after traumatic brain injury in rats. Journal of Neurosurgery, 116(5), 1081-1092.

Xu, H., Wang, Z., Li, J., Wu, H., Peng, Y., Fan, L., ... \& Chen, G. (2017). The polarization states of microglia in TBI: a new paradigm for pharmacological intervention. Neural Plasticity, 2017.

Yegla, B., \& Foster, T. C. (2019). Effect of systemic inflammation on rat attentional function and neuroinflammation: Possible protective role for food restriction. Frontiers in Aging Neuroscience, 11, 296.

Yong, V. W., Wells, J., Giuliani, F., Casha, S., Power, C., \& Metz, L. M. (2004). The promise of minocycline in neurology. The Lancet Neurology, 3(12), 744-751.

Zgaljardic, D. J., Seale, G. S., Schaefer, L. A., Temple, R. O., Foreman, J., \& Elliott, T. R. (2015). Psychiatric disease and post-acute traumatic brain injury. Journal of Neurotrauma, 32(23), 1911-1925.F

Zhang, Y., Chen, Y., Wu, J., Manaenko, A., Yang, P., Tang, J., ... \& Zhang, J. H. (2015). Activation of dopamine D2 receptor suppresses neuroinflammation through $\alpha \mathrm{B}$ crystalline by inhibition of NF- $\mathrm{KB}$ nuclear translocation in experimental ICH mice model. Stroke, 46(9), 2637-2646.

Zhao, X. H., Zhang, T., \& Li, Y. Q. (2015). The up-regulation of spinal Toll-like receptor 4 in rats with inflammatory pain induced by complete Freund's adjuvant. Brain Research Bulletin, 111, 97-103. 